\title{
FinAlLy MOVING BEYOND THE FICTION: AN OVERVIEW OF THE RECENT STATE RALLY FOR HEALTH CARE REFORM
}

\author{
Mark E. Douglas*
}

\section{TABLE OF CONTENTS}

I. INTRODUCTION

II. ARE STATES REALLY SETTING THE STAGE FOR FEDERAL

HEALTH CARE REFORM?

A. Why Are the States Pushing so Hard? A Brief Recap

of How We Arrived Here.

1. Costs and Consequences of the Uninsured

2. The Fallout From the Managed Care Movement.

$B$. The Federal Government's Response to Rising Health

Care Costs

1. Medicare Modernization Act: The Beginning of Something Good?

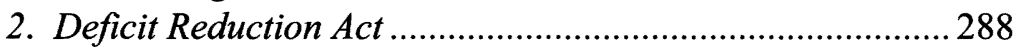

3. State Children's Health Insurance Program ........................ 288

III. STATES WITH PROMISING UNIVERSAL HEALTH CARE REFORM

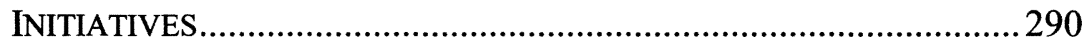

A. Major Movers in State Health Care Reform ............................. 290

1. Massachusetts-Commonwealth Care............................. 291

2. Maine-Dirigo Health ................................................... 293

3. Vermont-Catamount Health.......................................... 294

B. Other Promising State Initiatives ......................................... 295

1. California ...................................................................... 295

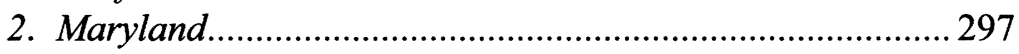

3. Pennsylvania ................................................................. 298

4. Indiana ......................................................................... 299

5. New Mexico................................................................. 300

IV. FUNDING ANALYSIS-HOW IS HEALTH REFORM BEING

FINANCED?

* J.D., 2008, Indiana University School of Law- Indianapolis, Indianapolis, Indiana; M.S.N., 1999, Indiana University, Indianapolis, Indiana; B.S.N., 1992, Indiana University, Indianapolis, Indiana. I would like to express my love and gratitude to my wife Kelly, my son Wyatt, and to my entire family for their love, support, and encouragement during law school. I would also like to thank Professors Eleanor Kinney and David Orentlicher for their support and for their continued leadership to make the Hall Center for Law and Health an internationally recognized academic institution and program. 


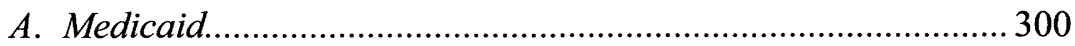

B. Mandated Employer and Consumer Coverage …...................... 301

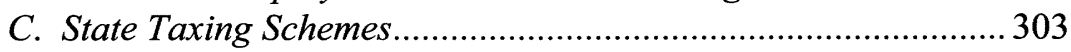

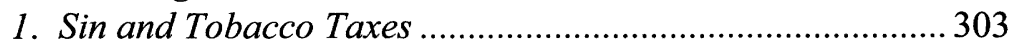

2. Provider and Insurer Taxes.................................................... 303

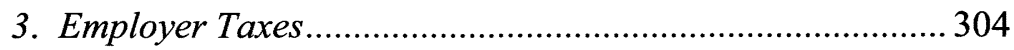

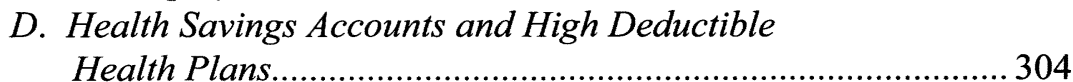

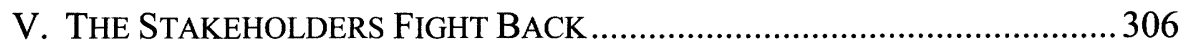

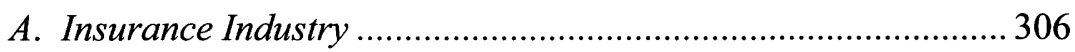

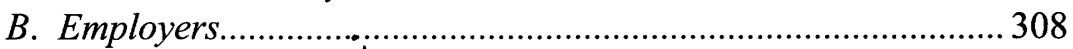

VI. AN UN-INTEGRATED SYSJEM: POLICY CONSIDERATIONS

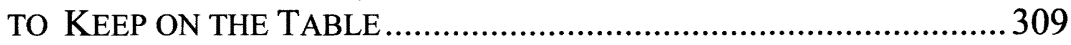

A. Information Technology ........................................................... 310

1. Electronic Medical Records and Regional Health

Information Organizations: Connecting the Health

Information Dots .............................................................. 310

2. Chronic Disease Management: Getting Control Early....... 313

3. Quality Measurement and Tracking: Excellence in Care Must Drive Reform ................................................ 315

B. Revisiting the Core Infrastructure: Patient Utilization and

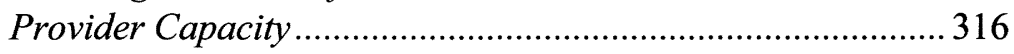

1. The Construction Re-Explosion and the Subsequent Reverberations.

2. Health Provider Shortage: The First Stumbling Block to Meaningful Reform............................................... 318

3. Emergency Department Utilization Rates ............................. 320

C. Bringing Back the Integrated Delivery System:

Can it Still Work?

1. Past Attempts in Developing an Integrated

Delivery System

2. Primary Care as the Center Piece for Integration ............... 325

a. The patient-centered primary care "home" concept.

b. Community Care of North Carolina: A successful primary care model.

D. Federal Action That Could Impact State Initiatives .................. 329

1. The Continued ERISA Problem.......................................... 329

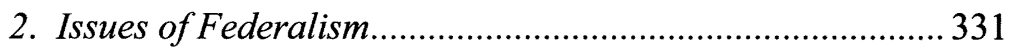

3. Prescription Drug Price Negotiations ............................... 332

VII. CONCLUSION- ARE WE THERE YET? ...................................................33

A. Reforming the Collective American Health Care Psyche........... 334

B. We Can No Longer Wait ........................................................... 336 


\section{INTRODUCTION}

With the number of uninsured expanding for the sixth year in a row, state governments have come under increasing political and economic pressure to take meaningful steps to put the brakes on out-of-control health care spending and address the increasing lack of access that many of their citizens face. While some states like Massachusetts, Maine, and Vermont have taken the lead in passing comprehensive health reform, almost every state in the United States is currently considering some measure or series of measures to expand coverage to their citizens. Although state reform efforts vary in size and scope, the momentum has clearly moved from a position of inertia to an outright kinetic frenzy to tackle this worsening crisis. With historic stakeholder action taking place at the grass-roots and state government levels, it appears significant federal action may finally be around the corner. Further adding to this reenergized appetite for reform, has been the fact that health care has become a contested and popular issue gaining notoriety in the 2008 presidential race. With so much energy swirling around health reform, perhaps the fictional movement that has been cloaked in "incremental steps" for the past two decades, will actually move to a factual and fundamental shift in the health care system that will provide for universal coverage for all Americans.

This Note will re-visit some of the major themes that have emerged within the health care reform debate that has been on-going for the better part of the past two decades. The major new initiatives that have been passed or which are now under consideration and represent the best possible examples of reform efforts will be examined in more detail. Part II of this Note will outline the continuing worsening affairs in the United States' health care system, will touch upon the federal government's response to the health crisis, and will discuss the by-products of the managed care era that are still relevant within the health care system today. Part III will examine the major health reform initiatives and discuss possible trends that may be emerging which could be applied on a national level or by other states. Part IV discusses the major funding sources that are being utilized to sustain current health reform efforts. Part V details the response of employers and insurers to state health care reform efforts. Finally, Part VI discusses important policy options that must be considered as part of any comprehensive federal health reform effort.

\section{ARE STATES REALLY SETTING THE STAGE FOR FEDERAL HEALTH CARE REFORM?}

\section{A. Why Are the States Pushing so Hard? A Brief Recap of How We Arrived Here}

With war raging in Iraq and the 2008 elections looming near, meaningful federal action regarding health reform has again been placed on hold amid the 
political posturing and rhetoric. The continued lack of federal will has ignited action by many states to reopen the testing grounds for implementing demonstration projects aimed at implementing health care reform ideas of their own. During this state push for reform, however, the federal government has remained a vested, if not distant partner in the process preferring to let each state make its own decisions about how to best design and implement health care reform solutions. At some point in this process, with so much at stake for the national economy and with a growing number of uninsured, the federal government must become more involved. The federal government's continued cooperation and collaboration will be essential in providing funding and guidance to craft solutions that make sense and are consistent with the national goals of building a sustainable, unified, and growing economy that promotes and provides for a healthier America. ${ }^{1}$

\section{Costs and Consequences of the Uninsured}

The recent flurry of state health care initiatives being introduced and enacted around the United States have been long awaited by many, and have created a renewed buzz that universal health care reform may actually be realized in the near future. Although reform efforts have been incrementally moving towards a "universal-like" solution over the past two decades, there has been a recurring failure of leadership by the federal government to take significant steps towards creating a health care system where every citizen can purchase or have access to affordable health care. ${ }^{2}$ In the mean time, states have slowly been taking action, tackling the complex issues created by the increasing number of uninsured and escalating health costs. The new state plans come at a time when the health care crisis is in an ever worsening state. Health care continues to sap the United States' economic strength with health care costs rising to over sixteen percent of the gross domestic product ("GDP") in $2004 .{ }^{3}$ Health

1. Theodore R. Marmor \& Jonathan Oberlander, Paths to Universal Health Insurance: Progressive Lessons From the Past for the Future, U. ILL. L. REV. 205, 217, 229 (2004) (discussing that regardless of the plan that emerges, the federal government will have shared authority over the states either as coordinator of services or as provider of oversight for funds distributed to each state for health reform purposes).

2. See BARry R. Furrow, Thomas L. Greaney, SANDRA H. Johnson, Timothy S. Jost \& RoBert L. SCHWARTZ, THe LAw OF HEALTH CARE ORGANIZATION AND FINANCE 136 (5th ed. 2003) [hereinafter FURROW ET AL.]. Although major health care reform efforts abruptly halted with the Clinton administration's failure to pass meaningful health reform, this movement did usher in a new era of health reform consciousness not seen since the Nixon years. As a result, there were modest achievements in health reform with the passage of the Health Insurance Portability and Accountability Act of 1996, and the creation of the State Children's Health Insurance Plan as part of the Balanced Budget Act of 1997.

3. Press Release, Ctr's for Medicare and Medicaid Services, Healthcare Spending Growth Rate Continues to Decline in 2004 (Jan. 10, 2006), http://www.cms.hhs.gov/apps/mdia/ press/release.asp? Counter $=1750 \&$ intNumPerPage $=10 \&$ checkDate $=\&$ checkKey $=\&$ srchType $=\&$ nuDays $=3500 \&$ srchOpt $=0 \&$ srchData $=\&$ keywordType $=$ All $\&$ chkNewsType $=1 \% 2 \mathrm{C}+2 \% 2 \mathrm{C}+3 \% 2 \mathrm{C}$ $+4 \% 2 \mathrm{C}+5 \&$ intPage $=\&$ showAll $=\& \mathrm{pYear}=\& \mathrm{year}=\&$ desc $=$ false $\&$ cboOrder $=$ date $($ last visited $\mathrm{Apr}$. 
care costs are predicted to increase from $\$ 1.6$ trillion in 2002 to $\$ 3.4$ trillion in 2013, consuming $18.4 \%$ of the GDP. ${ }^{4}$ Furthermore, the all too familiar statistics continue to indicate that forty-seven million individuals are currently without health insurance in the United States. ${ }^{5}$ Increasingly, those most at risk for uninsurance continue to be the working poor, part-time employees, selfemployed workers, young adults, and those with household incomes of less than $200 \%$ the federal poverty limit ("FPL"). ${ }^{6}$ However, one of the fastest growing segments of the uninsured is working low-middle, to middle class individuals and families with incomes at or below $400 \%$ FPL.?

Not surprisingly, in the midst of this worsening trend is a growing lack of confidence by consumers that continues to intensify as average insurance premiums consistently rise to levels above the rate of inflation. ${ }^{8}$ Additionally, many uninsured are left in an undertow of debt, stricken with unpaid medical bills which have propelled the skyrocketing number of personal bankruptcy claims. ${ }^{9}$ With access to affordable care lagging, a growing number of Americans have become increasingly dismayed with the current state of the entire health care system, and rate the care they receive as fair and in many instances poor. ${ }^{10}$

26, 2008).

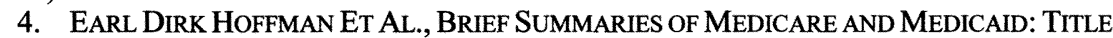
XVIII AND XIX OF THE SOCIAL SECURITY ACT 5 (2004), available at http://www.cms.hhs.gov/ MedicareProgramRatesStats/downloads/MedicareMedicaidSummaries2004.pdf.

5. Carmen Denavas-Walt, Bernadette D. Proctor \& Jessica Smith, U.S. Census BurEAU, INCOME, POVERTY, AND HEALTH INSURANCE COVERAGE IN THE UNITED STATES: 2006, 18 (2007), available at http://www.census.gov/prod/2007pubs/p60-233.pdf.

6. Id. at 20-2.

7. JOHN HOLAHAN \& ALLISON COOK, KAISER COMM'N ON MEDICAID \& THE UNINSURED, Why Did THE Number OF UNINSUREd CONTINUE TO INCREASE IN 2005? 6 (Oct. 2006), $\mathrm{http}: / / \mathrm{www} . \mathrm{kff} . o r g /$ uninsured/upload/7571.pdf (noting the largest growing group among those without insurance were those with household incomes over $\$ 50,000$ ).

8. ABC NEWS/Kaiser FAM. Found./USA TODAY, HEALTH CARE IN AMERICA 2006 SURVEY (2006), http://www.kff.org/kaiserpolls/upload/7572.pdf [hereinafter ABC KAISER SURVEY] (discussing how health care costs rose $7.7 \%$ in 2006 or twice the rate of inflation).

9. Id. (revealing increased cost and financial constraint as the main reasons for dissatisfaction and noting an alarming increase in the number of uninsured delaying care to avoid accumulating debt). See also Michelle M. Doty et al., Seeing Red: Americans Driven into Debt by Medical Bills, THE COMMONwEALTH FUND, Aug. 2005, http://www.cmwf.org/usr_doc/837 Doty_seeing_red_medical_debt.pdf(noting that thirty-seven percent of adults nineteen and older ( $7 \overline{7}$ million Americans) have trouble paying for medical care and that debt related to health care expenses account for forty to fifty percent of all personal bankruptcies filed). But cf. David Dranove \& Michael L. Millenson, Medical Bankruptcy: Myth Versus Fact, 25 HeALTH AfF. w74, w74- w83 (2006) (research indicates the actual number of personal bankruptcies attributable to medical bills is only seventeen percent. Most individuals filing bankruptcy are not middle class, but are instead in low-middle to lower economic classes).

10. Ruth Helman, Mathew Greenwald \& Associates \& Paul Fronstin, 2006 Health Confidence Survey: Dissatisfaction With Health Care System Doubles Since 1998, EBRI NoTES, Nov. 2006, at 2-12, available at $\mathrm{http} / / / \mathrm{www}$. ebri.org/pdf/notespdf/EBRI_Notes_11-20061.pdf (noting six in ten Americans rate the overall health care system as fair or poor even though fiftytwo percent rate the quality high. See also ABC KAISER SURVEY, supra note 8 (reporting six in ten dismayed over quality and costs of the health care system). 
Businesses are also applying political pressure to find economic solutions to the health care problem which is straining their ability to remain competitive in the quickly expanding global economy. In particular, smaller businesses that spur most of the new job growth in the country, especially those with less than 500 employees, are increasingly less likely to provide health insurance coverage to their employees, leaving as many as forty million workers without health care. ${ }^{11}$ In 2006, the number of Americans with employer-based insurance dropped below sixty percent for the first time. ${ }^{12}$ This has led to a trickle down effect where many employee dependents are also left without coverage. ${ }^{13}$ With increasing numbers of employers dropping health benefits, insurance companies have not provided alternatives or corrections to the managed care phenomenon which has ultimately failed to control rising costs and expand coverage to workers. ${ }^{14}$

\section{The Fallout From the Managed Care Movement}

The structural changes that emerged from the managed care era have created a system with serious disconnects in the provider continuum. Managed care attempts made during the past two decades to transform and integrate the health care delivery system, by introducing a broad array of public and privatesponsored health plans and programs, focused on cost-containment, utilization and review controls that ultimately restricted provider choice. They have failed in many respects to create the affordable and accessible markets that were envisioned for consumers. ${ }^{15}$ While a complete discussion of these past successes and failures is beyond the scope of this Note, it can be safely asserted that the resulting effect of managed care has been marked by significant consolidation over the past two decades which has lead to intense competition between doctors, insurers, and hospitals for market share and managed care contracts. This competition has brought about the formation of local and regional health networks that have in many instances crowded both providers and consumers out

11. James D. Reschovsky, Bradley C. Strunk \& Paul Ginsberg, Why Employer-Sponsored Health Insurance Coverage Changed, 1997-2003, 25 HEALTH AFF. 774, 774-82 (2006) (noting that nine million lost health insurance coverage from 2001-2003 for many reasons including the economic downturn that occurred after September 11, 2001, increased costs of premiums to employers, and the fact that health care costs grew faster than wages). See also Ann Hilton Fisher, Small Employers and the Health Insurance Needs of Employees with High Health Care Costs: A Need For Better Models, 8 EMP. RTs. \& EMP. PoL'Y J. 53, 55-6 (2004).

12. See DeNAVAS-WALT ET AL., supra note 5, at 20.

13. Laura D. Hermer, Private Health Insurance in the United States: A Proposal For A More Functional System, 6 Hous. J. HEALTH L. \& POL'Y 2, 19-20 (2005).

14. Marmor \& Oberlander, supra note 1, at 208-209 (2004) (noting HMOs were never truly effective at containing health care costs. HMOs ultimately played a key role in creating an environment where medical inflation was twice the consumer price index by mid-2002).

15. See generally MARK HALL, MARY ANNE BOBINSKI \& DAVID ORENTLICHER, HEALTH CARE L. \& ETHICS, 935-42 (6th ed. 2003) [hereinafter HALl ET AL.]. See also John V. Jacobi, Dangerous Times for Medicaid, 33 J.L. MED. ETHICS 834, 840-41 (2005). 
of the market. ${ }^{16}$ As a result, the new health care paradigm that has emerged no longer recognizes the traditional, top-heavy, physician-led community hospital system, but instead is increasingly giving way to an unforgiving model of efficiency driven by economic and market pressures to contain costs. ${ }^{17}$ While this fundamental shift invites many questions about how effectively health care is now being utilized in this new era, two key changes did emerge in redefining how hospital systems currently do business: the large number of hospital mergers and the emergence of specialty hospitals.

With the emergence of aggressive competition between providers, and the increased need to stay relevant and expand their geographic presence in the managed care market, many hospitals have been forced, by thinning margins created by decreased reimbursement rates from third party payers and the federal government, to join together with former competitors and large physician groups. ${ }^{18}$ In addition, specialty physicians caught in the cross-fire of trying to retain economic control of their practice became increasingly unhappy with their managed care relationships with hospitals as the ability to get their fair share of the shrinking reimbursement pie decreased, a trend that eventually led to the emergence of specialty hospitals. ${ }^{19}$ The proliferation of specialty hospitals resulted in many lucrative service lines such as cardiac, orthopedic, laboratory, and imaging services being stripped from hospital profit centers. ${ }^{20}$ In response, hospitals have renegotiated financial relationships with physicians, leading to the creation of joint ventures and other collaborative partnerships in an attempt to maintain their revenue targets and position in the marketplace. ${ }^{21}$

As the health care system has morphed through the various versions of managed care, states have faced rapidly growing costs resulting from the need to pay for state employee health benefits, public health programs such as Medi-

16. See FURROW ET AL., supra note 2, at 535-40 (While the dynamics of the integration that occurred under managed care are complex, the delivery system that emerged often favored hospitals and insurers who had deeper pockets to re-structure the system in their favor to win managed care contracts. As a result there was both "horizontal integration" (physician group mergers, hospital mergers) and "vertical integration" (hospitals and physicians entering into partnerships and affiliations to create "one-stop-shopping" and many instances their own HMO to maximize geographic coverage needed to leverage economic power with employers when selecting their managed care provider. The integration phenomena, however was followed by many bankruptcies of hospitals and HMOs who spent too much money to buy physician practices or failed to manage risks properly).

17. James F. Blumstein, The Application of Antitrust Doctrine to the Healthcare Industry: The Interweaving of Empirical and Normative Issues, 31 IND. L. REV. 91, 92-4 (1998) (outlining the change in the health care marketplace from a system driven by a pure physician-led professional model to a more open market system where the physician decision-making and utilization patterns are now subject to market forces).

18. HALl ET AL., supra note 15, at 1042-50.

19. FURROW ET AL., supra note 2, at 545-46.

20. FinANCING THE FUtURe II REPORT 4: JoINT Ventures With Physicians AND Other PARTNERS, HEAlTHCARE Fin. MGMT. Ass'N, Feb. 2006, at 4-10, available at http://www.hfma. org/NR/rdonlyres/4CD52880-DC83-469B-A9E6-D1072A75C455/0/FNF2_No_4.pdf[hereinafter FINANCING THE FUTURE].

21. FURROW ET AL., supra note 2, at 545-46. 
caid, and the increased demands that the uninsured have placed on the safety net system including community hospitals and community health centers. ${ }^{22}$ The increased demand for complex and technologically advanced care for an aging Medicaid and Medicare population, in a system complicated by a weakened community hospital infrastructure and a shortage of key health providers, has also complicated the ability to provide health coverage. Further, for many without coverage, the health care environment has become a high-stakes health care poker game where many uninsured consumers put off obtaining necessary health services until it becomes a critical necessity. The result is an unhealthier population where basic health care needs are not being met. ${ }^{23}$ And when the uninsured finally do seek health services, the financially strapped emergency rooms of safety net hospitals and community health centers ("CHC") often become the default primary care providers. ${ }^{24}$ Many safety net hospital systems that are disproportionately caring for the uninsured are sustaining financial losses that threaten their existence. With safety net systems on the ropes, other nonprofit and for-profit hospitals are not only shifting more resources to care for the uninsured, but also worrying about their fate as the health care crisis unravels. $^{25}$

Faced with one of the most important modern political and economic challenges, states have determined the status quo is unacceptable and are challenging what is quickly becoming an outdated health care system entangled with an employer-based insurance model that is no longer working effectively. Complicating this phenomenon is the increased consumer demand for the latest

22. Bruce C. Vladeck, Paying for Hospitals' Community Service, 25 HeAlth AfF. 34, 3443 (2006) (Hospitals in the country spend approximately $\$ 30$ billion on uncompensated care which inevitably gets cost-shifted to the insured (through increased premiums and co-pays) where there is a smaller pool of individuals able to cover actual costs incurred by hospitals. General hospitals operating are having trouble maintaining their mission to provide health professional training, and provide care for their community, especially in rural and underserved urban areas). See also Michael K. Gusmano et al., Exploring the Limits of the Safety Net: Community Health Centers and Care for the Uninsured, 21 HEALTH AFF. 188, 188-94 (2006) (CHCs serve an important role in the "patchwork" system that provides basic health services to the uninsured, but $\mathrm{CHCs}$ are now under increasing stress to provide additional services such as specialty care and advanced diagnostics. CHCs should be given more funding to expand care and services to the uninsured as they already play a vital role in the health care delivery system in many underserved communities).

23. Bruce Siegel, Marsha Regenstein \& Peter Shin, Health Reform and the Safety Net: Big Opportunities; Major Risks, 32 J.L. MED. \& ETHICs 426, 428 (2004) (noting the uninsured receive less preventive health care, leading to an increased likelihood of advanced chronic disease relative to the insured population).

24. Id. at $426-27$.

25. Id. at 427-28 (discussing that safety net hospitals are under increasing pressure to rethink their business strategy, and in many cases, face closure due to the increasing demands placed upon their hospital, the uninsured and shrinking reimbursement). But cf. Jack E. Karns, Justifying the Nonprofit Hospital Tax Exemption in a Competitive Market Environment, WIDENER L. REV. 383, 415-25 (2004) (discussing many non-profit hospitals actually benefit from providing a certain amount of non-reimbursable care to the uninsured by protecting the hospital's nonprofit status, thereby avoiding taxation). 
and most advanced health care technology available, a demand that often fails to consider how payment for the services is to be provided. As states realized that substantive federal action was not available to help solve these complex issues, they have taken the driver's seat to prevent their problems from skidding further out of control. Whether states will get the federal help they need to continue reform efforts remains to be seen, but voters during the current 2008 presidential election have once again made the issue of national health care reform into a red-hot topic. Voters are showing renewed interest in domestic issues and are clamoring for attention to concerns beyond the war in Iraq. Specifically, health care reform ranks as a very important issue that voters want addressed by their government leaders. ${ }^{26}$

\section{B. The Federal Government's Response to Rising Health Care Costs}

So where is the federal government leadership in this crisis today? Many would suggest the federal government lost its appetite for health care reform after previous administrations, as demonstrated under President Clinton, ultimately failed to provide a palatable, user-friendly approach to health care reform. ${ }^{27}$ The current administration, under President Bush has done little during its time in office to seriously address the issue of expanding health coverage to all Americans. Instead, as President Bush again noted in both the 2007 and 2008 State of the Union addresses, the President has continued to push a strategy for health care reform focused on consumer choice that hinges on tax credits for citizens, increased use of HSAs, and the utilization of association plans for employers. ${ }^{28}$ On Capitol Hill, there have been few initiatives worth noting that have addressed the universal health coverage issue. Only one legislative effort has addressed universal coverage head-on. Representative John Conyers introduced House Bill 676 on February 8, 2005, which proposed a nationalized health plan run under a federally coordinated single-payer system. Seventyseven co-sponsors have signed on in support, but the bill has failed to gain sufficient traction to move forward. ${ }^{29}$ It should be noted, however, that there are several federal legislative efforts that have ultimately informed the reform discussion since the Clinton reform movement. Although an analysis of every legislative action, and its effect on the health care system, is beyond the scope of

26. Kaiser Health Tracking Poll: Election 2008, http://www.kff.org/kaiserpolls/ h08 pomr030708pkg.cfm (last visited Apr. 20,2008) (noting that health care consistently ranks among Democrats, Republicans, and independents as the most important voter issue behind the Iraq war and the economy).

27. Marmor \& Oberlander, supra note 1, at 211-13 (recounting President Clinton's inability to muster support from Congress and popular support from U.S. citizens who saw Clinton's plan as another inappropriate expansion of "big government").

28. The Whitehouse, Strengthening Health Care, http://www.whitehouse.gov/infocus/ healthcare (last visited Apr. 20, 2008).

29. United States National Health Insurance Act, H.R. Res. 676, 109th Cong. 1st Sess. (2005). 
this Note, the enactment of the Medicare Prescription Drug Improvement and Modernization Act of 2003 ("MMA"), Deficit Reduction Act of 2005 ("DRA"), and the creation of State Children's Health Insurance Program ("SCHIP") were all federal legislative strategies that have impacted the health care system and health reform efforts in some manner. ${ }^{30}$

\section{Medicare Modernization Act: The Beginning of Something Good?}

The Medicare Modernization Act was passed under heavy scrutiny in 2003. ${ }^{31}$ The MMA was most notable for redefining drug benefits for Medicare recipients and expanding the use of Health Savings Accounts ("HSA") that effectively solidified the new era of "consumer-driven health care" ("CDHC"). ${ }^{32}$ Most contentious was the restructuring of the "Part D" prescription benefits for Medicare recipients which created a new payment and insurance restructuring that was designed to help subsidize the medications costs associated with the drug entitlement. Essentially, Part D now requires Medicare enrollees to pay a deductible and monthly payment or portion of all drug costs up to $\$ 2250$, with a "donut hole" provision that then requires beneficiaries to pay up to $\$ 3600$ out of pocket for medications before coverage kicks in again. ${ }^{33}$ The Part D restructuring has met with mixed results. ${ }^{34}$ While overall drug coverage has increased to seniors, out-of-pocket costs have increased as well. The government, however, has realized cost-savings with the new Part D implementation. Indeed, it is now predicted that the new Part D programs that emanated from the MMA are likely to save $\$ 113$ billion dollars over the next ten years. ${ }^{35}$

30. Medicare Prescription Drug, Improvement and Modernization Act of 2003, Pub. L. No. 108-173, § 1201, 117 Stat. 2066, 2071 (2003); Deficit Reduction Act of 2005 (Pub. L. 109171, 120 Stat. 4) (2006); Balanced Budget Act of 1997, Pub. L. 105-33, 111 Stat. 251, (codified as amended 42 U.S.C.A. $\S \S 1397$ aa (1997).

31. During the passage of the MMA, there were several discrepancies over what the program would actually cost and evidence later arose that indicated the Bush administration misrepresented the total costs in order get the bill past fiscally-minded Republicans. In addition, the MMA prevents the government from negotiating discounts with the drug companies and prevents the federal government from establishing a national formulary both of which could reduce costs.

32. Timothy S. Jost \& Mark A. Hall, The Role of State Regulation on Consumer-Driven Health Care, 31 AM. J.L. \& MED. 395, 396 (2005) (defining consumer driven health care as a general understanding that too many Americans are "generously" insured and therefore need to incur more of the financial burden of paying for care, which will in turn help drive down overutilization of health care services). See also Medicare Prescription Drug, Improvement and Modernization Act of 2003, Pub. L. No. 108-173, § 1201, 117 Stat. 2066, 2071 (2003).

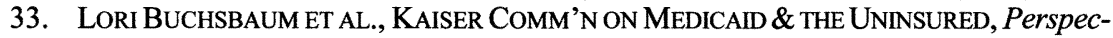
tives on Medicare Part D and Dual Eligibles: Key Informants' Views From Three States, available at http://www.kff.org/medicaid/upload/7639.pdf.

34. Commonwealth Fund, Study Finds Medicare's Drug Benefit Substantially Increased Coverage Among Seniors, But Some Continue to be Vulnerable to High Costs, August 21, 2007 , http://www.commonwealthfund.org/newsroom/newsroom_show.htm?doc_id=516616 (last visited Apr. 20, 2008).

35. Press Release, Centers for Medicare and Medicaid Services, Medicare Drug Plans 
With respect to HSAs, although stronger incentives were provided under the MMA to increase HSA use, many experts question whether the new wave of CDHC that has followed in an attempt to correct escalating costs will have the predicted net effect of decreasing health care utilization or creating a broad economic benefit for all socioeconomic classes. ${ }^{36}$ Critics of the President's plan cite that the HSA changes will help the more well-off, and will only benefit three to five million of the uninsured, leaving the bulk of citizens without insurance and with no other way to obtain reasonable coverage. ${ }^{37}$ (HSAs and high deductible health plans are discussed in more detail below under Section IV).

The MMA also authorized the Citizens' Health Care Working Group which was comprised of various health care experts and citizens who were asked to examine the current health care crisis and make recommendations to improve health care access and quality. The final report, published September 26,2006 , validated a list of recurring themes that emerged from town hall meetings with citizens and discussions with industry experts but did not clearly advocate any specific reform or plan. ${ }^{38}$ Six general themes were identified as key health reform benchmarks: 1) establishing a public policy that all Americans have affordable health care; 2) guaranteeing financial protection against very high health care costs; 3 ) fostering innovative integrated community health networks; 4) defining the core benefits and services that will be assured to all Americans; 5) promoting efforts to improve quality of care and efficiency; and 6) restructuring end-of-life care so that people of all ages have increased access to needed services in the environment they choose. ${ }^{39}$ This report has not appeared to have much impact on national health care reform efforts or inspired action under the Bush administration. It is worth noting, however, that the group did recommend the federal government provide affordable coverage for all Americans by $2012 .^{40}$

Strong and Growing (Jan. 30, 2007).

36. Hermer, supra note 13, at 4-5. See also Catherine Hoffman \& Jennifer Tolbert, Health Savings Accounts and High Deductible Plans: Are they an Option for Low-Income Families?, HeNRY J. KAISER FAM. Found., KAISER COMM'N ON MEDICAID \& THE UNINSURED, Oct. 2006, http://www.kff.org/uninsured/upload/7568.pdf (revealing that the income levels of low income families do not favorably match with the economics of HSAs, making HSAs an infeasible method for containing health care costs across the economic spectrum).

37. See Amanda Gardner, Bush's Health Care Proposal Inadequate: Critics, HeAltH DAY NEwS, Jan 24, 2007, http://www.washingtonpost.com/wp-dyn/content/article/2007/01/ 24/AR2007012400922.html (last visited Apr. 20, 2008).

38. Citizens' health Care Working Group, Health Care That Works for All AMERICANS, (2006), http://www.citizenshealthcare.gov/recommendations/finalrecommenda tions_print.pdf.

39. Id. at 5 .

40. Id. 


\section{Deficit Reduction Act}

The DRA was passed in 2005 and signed into law by President Bush in 2006 as a measure to control the federal government's entitlement spending. ${ }^{41}$ The DRA laid out a cost savings plan of $\$ 26.3$ billion, which encompassed a broad array of programs including Medicare and Medicaid, to be realized over a period of time from 2006-2015. Although many believe the DRA will have a deleterious effect on the provision of some community services, some contend that the DRA has created a new opportunity for some states by promoting significant changes in funding for modernization efforts. Such funding has allowed more flexibility for states administering their Medicaid programs. ${ }^{42}$ With respect to modernization, the DRA has provided $\$ 150$ million in "Transformation Grants," grants which have been used to support state efforts ranging from technology upgrades for chronic disease management programs to technologyfocused strategies to improve the quality of care. ${ }^{43}$ Further, under the DRA states have been given increased authority with respect to 1115 demonstration waivers to increase expansion of Medicaid by allowing higher-income individuals to participate. Several states have taken advantage of this new DRA provision and have gone on to integrate high-deductible plans to increase costsharing with enrollees as a means to increase coverage. But while the DRA provides, it also takes away. The new DRA provisions also tightened the requirement for providing proof of citizenship to receive access to federal entitlements. ${ }^{44}$ This new requirement has been linked to decreased Medicaid enrollment and acceptance rates across many states and, as a result, has been challenged in court. ${ }^{45}$ While the DRA provisions have "slowed" the growth of Medicaid and other entitlement application rates, it appears that in the end it may be in part a self-defeating measure as some individuals who would have otherwise legitimately qualified will be left uninsured.

\section{State Children's Health Insurance Program}

The State Children's Health Insurance Program ("SCHIP”) was authorized by Congress as part of the Balanced Budget Act of 1997 as a joint federal and state funded program administered by the states which has since cost about for-

41. Deficit Reduction Act of 2005, Pub. L. 109-171, 120 Stat. 4 (2006).

42. Id. at $\S 6081$.

43. Id. See also CMS, MEDICAID TRANSFORMATION GRANTs, http://www.cms.hhs.gov/ Med icaidTransGrants (last visited Apr. 20, 2008).

44. See Deficit Reduction Act $\S 6036$.

45. Bell v. Leavitt, No. 06 C 3520, 2007 WL 551553 (N.D. Ill. Feb 16, 2007). The court denied the class action challenge as the plaintiffs failed to properly articulate a constitutionally or legally viable challenge to the DRA statute. As a result of this case, however, the Bush administration later exempted over 8 million Supplemental Security Income and Medicare beneficiaries as well as a number of children receiving benefits via adoption or foster care assistance programs. 
ty billion dollars. ${ }^{46}$ The purpose for enacting the SCHIP program was to reduce the number of low-income uninsured children in the United States - especially among those families who exceed eligibility for Medicaid benefits. SCHIP is not an entitlement program but is rather a state-run program that provides fixed funding for limited benefits to qualified enrollees. Each State may design its own program, but must follow pre-determined federal guidelines when outlining parameters such as eligibility, payment levels for coverage, and administrative and operating procedures. ${ }^{47}$ Generally, SCHIP funding is targeted to cover uninsured children whose families have income that exceeds Medicaid eligibility, but are at or below the $200 \%$ FPL. Fourteen states have waivers which allow for coverage of some adults, parents and caretakers of SCHIP-eligible children, pregnant women, and childless adults. Forty-one states have chosen to cover children in families at $200 \%$ the FPL or higher with seven states providing coverage up to $300 \%$ FPL. ${ }^{48}$ Under current law, states are prohibited from providing SCHIP benefits to illegal immigrants who have been in the U.S. less than five years, undocumented children, children of the state and public employees, children over age eighteen, and/or children who already have private coverage.

In its first year, SCHIP enrolled 897,000 children rising to 4.1 million children enrolled in the United States as of June 2006. Since SCHIP's inception ten years ago, as many as six million enrollees have been covered, including 639,000 adults. ${ }^{49}$ However, nine million children who are eligible for SCHIP funding remain uncovered in the United States. Some states have seen decreases in SCHIP coverage. But the overwhelming majority of states have been increasing coverage as result of the loss of employer-sponsored insurance and the increase in the number of parents who were once on Medicaid, are no longer eligible, and now qualify for SCHIP.

In July 2007, both Houses of Congress passed the re-authorization of the SCHIP program which went to the President for approval. In the negotiations that lead up to the final vote, the President proposed a five billion dollar increase in funding whereas the House proposed a fifty billion dollar increase, and the Senate a thirty-five billion dollar increase. ${ }^{50}$ In order to pay for the

46. Balanced Budget Act of 1997, Pub. L. 105-33, 111 Stat. 251, (codified as amended 42 U.S.C.A. $\$ \S 1397$ aa (1997) (TITLE XXI-State Children's Health Insurance Program). The Centers for Medicare and Medicaid Services ("CMS") and Department for Health and Human services ("DHHS") have federal oversight for all State Medicaid and SCHIP programs.

47. GAO Highlights, States' SCHIP Enrollment and Spending Experiences and Considerations for Reauthorization, Feb. 15, 2007, available at http://www.gao.gov/new.items/ d07501t.pdf; see also George Washington University Center for Health Services Research and Policy, Policy Brief \#6, From SCHIP Benefit Design to Individual Coverage Decisions, http://www.gwumc.edu/sphhs/healthpolicy/chsrp/downloads/SCHIP_brief6.pdf.

48. KAISER COMM'N ON MEDICAID \& THE UNINSURED, SCHIP TURNS 10: AN UPDATE ON ENROLLMENT AND THE OUTLOOK ON REAUTHORIZATION FROM THE PROGRAM'S DIRECTORS, (May 2007), available at http://www.kff.org/medicaid/upload/7642.pdf.

49. Id. at 6 .

50. KaISER COMm'N ON MEdicaid \& THE UNINSURED, SCHIP: REAUTHORIZATION 
SCHIP expansion Congress considered a federal cigarette tax of up to $\varnothing .61$. In the end, no compromise could be reached, and the President vetoed the bill. The President issued the veto stating many of his constituents were against any major funding increases for SCHIP because it would have the effect of creating an incentive for some parents to opt out of employer coverage to qualify for SCHIP; thereby, causing SCHIP to insure middle-income children that the program was never designed to cover. Much of the controversy over SCHIP stemmed from the increase in family income that would have increased eligibility to families at $300 \%$ FPL or $\$ 63,000$ for a family of four. ${ }^{51}$ Those in favor of the SCHIP re-authorization, fearing a failure to re-up the program would further worsen the uninsured problem, felt that the expansion was critical to getting health care services to more children. ${ }^{52}$ Some see SCHIP as a good faith effort to cover children while others worry that SCHIP represents a major step towards a single-payer federally funded mandate for universal health care. The SCHIP debate will likely heat up again, perhaps even in the context of health reform, but the next debate will come under a new president as President Bush signed an extension which will fund SCHIP through March, 2009.

\section{STATES With PROMISING UNIVERSAL HEALTH CARE REFORM INITIATIVES}

\section{A. Major Movers in State Health Care Reform}

Over twenty states have recently offered innovative answers to the financially and morally perplexing issue of health care consumption and the uninsured. $^{53}$ With the average state spending twenty-two percent of its budget on Medicaid costs alone, states are no longer idly standing by to watch their budgets fall under the weight of continued uncontrollable health care costs. ${ }^{54}$ As each state moves forward with unique health reform programs to meet their specific geographic and socioeconomic requirements, various elements are beginning to emerge that may be applicable in the future reform efforts of every state. For purposes of this discussion, the promising aspects of three compre-

HiSTORY, (Jan. 2008), available at http://www.kff.org/medicaid/upload/7743.pdf.

51. Martin Kady, House Fails to Muster SCHIP Veto Override, PolTiCo.com, Oct. 18, 2007, http://www.politico.com/news/stories/1007/6438.html (last visited Apr. 20, 2008).

52. Mary E. Rimsza, Richard J. Butler, \& William G. Johnson, Impact of Medicaid Disenrollment of Health Care Use and Costs, 119 PeDIATRICs 5, e1026-32 (May 2007). The authors conducted a retrospective review of the utilization records of thousands of children who were enrolled in Arizona's Medicaid/SCHIP program. The team showed that a ten percent reduction in enrollment led to an increase in costs of $\$ 2121$ yearly for each disenrolled child caused by expenses related to substantial increases in emergency utilization and in-hospitals stays.

53. NAT'L CONFERENCE OF STATE LEGISLATURES, HEALTH REFORM Bills, http://www.ncsl. org/programs/health/universalhealth2007.htm (last visited Apr. 20, 2008).

54. NAT'L GOVERNORS ASSOCIATION AND THE NATIONAL ASSOCIATION OF STATE BUDGET OfFicers, The FisCAL SURVEY OF STATES (2007), http://www.nasbo.org/Publications/PDFs/ Fiscal $\% 20$ Survey $\% 20$ of $\% 20$ the $\% 20$ States $\% 20 J u n e \% 202007$.pdf. 
hensive state plans, Massachusetts, Maine, and Vermont will be discussed in greater detail. In addition, compelling aspects of other emerging plans will be examined with regard to innovative ideas that may provide insight into strategies that could be adopted by other states or as part of a national reform effort.

\section{Massachusetts-Commonwealth Care}

Massachusetts has been in the process of rolling out its new universal health care plan, "Commonwealth Care," to cover its 600,000 uninsured citizens. This plan is one of the first comprehensive plans in the country that is dedicated to a universal health model. The bipartisan plan was passed in March 2006 and signed into law by then Governor Mitt Romney on April 12, 2006. ${ }^{55}$ The Massachusetts plan uniquely mandates participation for all citizens and employers. $^{56}$ Those individuals who fail to enroll can lose their personal state income tax deduction and face additional fines of up to fifty percent of the lowest priced insurance that can be afforded. ${ }^{57}$ Employers with more than ten employees who fail to provide insurance coverage are required to contribute a "fair share" yearly payment of $\$ 295$ per employee. ${ }^{58}$ The fair share payment paid by employers is allocated to the general Commonwealth Fund to cover the uninsured. In addition, employers will be required to set up Section 125 cafeteria plans that will allow employees to purchase health care insurance in the new plan with pre-tax income. ${ }^{59}$

Massachusetts has utilized a quasi-governmental entity, the Commonwealth Care Insurance Connector ("Connector"), which has functioned as the central administrating agency linking individuals and employers to six insurance products subsidized by the state. The plans were selected based on their ability to provide comparable services similar to what would be purchased on the open market and are portable upon a change in employment. Subsidized coverage is provided for an individual or family with an income up to $300 \%$ FPL. ${ }^{60}$ Individuals can purchase subsidized insurance that will require payment of a monthly premium based on an income sliding-scale in addition to a stan-

55. See 2006 MASS. ACTS ch. 58.

56. Id.

57. Jeffrey Krasner, Sign-up Push is on for Health Coverage: Sweeping State Law Gets a Major Test, BosTON.COM, Dec. 29, 2006, available at http://www.boston.com/news/local/ massachusetts/articles/2006/12/29/sign_up_push_is_on_for_health_coverage/ (last visited Apr. 20, 2008).

58. Beth Waldman, Massachusetts Health Care Reform: Using an 1115 Waiver to Provider Private InSURANCE to Contain Costs (2006), http://www.nhpf.org/handouts/ Waldman.slides 05-16-06.pdf.

59. Id. Section 125 cafeteria plans are authorized under the Internal Revenue Code which provides employers the ability to allow employees to purchase health insurance with pretax dollars; see FAQs for Government Entities Regarding Cafeteria Plans, http://www. irs.gov/govt/fslg/article/0, id=112720,00.html\#1 (last visited Apr. 20, 2008).

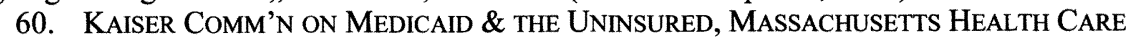
REFORM PLAN: AN UPDATE (2007), http://www.kff.org/uninsured/upload/7494-02.pdf. 
dard co-payment for office visits and hospital stays. ${ }^{61}$ Individuals with less than $100 \%$ FPL will not be required to pay premiums. The health plans cover many inpatient and outpatient services including coverage for inpatient and outpatient care, mental health and substance abuse treatment, vision care, dental care, hospice care, emergency care, and certain rehabilitation services. ${ }^{62}$

Massachusetts' plan was predicted to cost $\$ 1.2$ billion over a three-year period. Funding for the plan was initially paid for by a complex scheme involving Medicaid expansion to cover children, a Medicaid 1115 waiver, and the mandate payment schedule previously described. ${ }^{63}$ As of April, 2008, the Commonwealth plan had enrolled 174,000 individuals but reported a budget shortfall of $\$ 153$ million. ${ }^{64}$ For the upcoming fiscal year, 2008-2009, Governor Deval Patrick has requested $\$ 869$ million to fund the Commonwealth Care program, up from $\$ 472$ million budgeted the previous year. Since the inception of the program about 340,000 of the uninsured have acquired insurance either through the Connector or as required under the mandate. In addition, the dollars that were previously allotted to safety net hospitals for providing increased uncompensated care have been reallocated to a Health Safety Net Trust Fund, which has paid safety net providers out of a combined fund of Medicaid and disproportionate share fund dollars ("DSH"). As more people enroll in the new plan and as uncompensated care decreases, the money in the Safety Net Trust Fund will be shifted to the Commonwealth subsidy plan to expand coverage to the uninsured pool. ${ }^{65}$

The innovative Massachusetts plan has many stakeholders and policymakers around the country looking closely at the various parts of the package, especially the Connector. Although it is not clear if the uninsured will completely benefit from the plan, the Connector does provide options for many who might otherwise not be able to secure coverage. The Connector's strengths lies in the fact that it creates a centralized structure that combines a unique utilization of insurance products and premium subsidies through an exchange that provides consumers and employers affordable insurance options that can be used to expand coverage and provide portability. While it appears future funding and cost control will be an on-going issue, the Commonwealth plan is in front, leading the reform charge with the passage of this bold program.

61. Id.

62. Commonwealth Care Commonly AsKed Questions, http://www.mass.gov/ Eeohhs2/docs/masshealth/memlibrary/commonwealthcare-faqs-eng.pdf.

63. Id. See also 2006 MASs. AcTs ch. 58.

64. Kevin Sack, Universal Health Care to Cost Massachusetts More Than Was Budgeted, NYTIMES.COM, Apr. 17, 2008, available at http://www.nytimes.com/2008/04/17/us/ 17brfs-UNIVERSALHEA_BRF.html (last visited Apr. 20, 2008).

65. WALDMAN, supra note 58. 


\section{Maine-Dirigo Health}

Although it was launched to less fanfare than the Massachusetts plan, in June 2003, Maine was one of the first states to respond to rising health care costs and the lack of health insurance coverage with the passage of the Dirigo Health Reform Act. ${ }^{66}$ The voluntary plan is an incremental approach intended to cover the 130,000 uninsured in the state by $2009 .^{67}$ The Dirigo Health Agency was created to work in conjunction with the state Bureau of Insurance and Department of Health and Human Services to provide collaboration and oversight for the subsidized health plan. Key components of the legislation included the passing of several progressive cost-reducing measures and the creation of a state-sponsored health plan administered by a private insurer. ${ }^{68}$ Cost containment measures highlighted in the plan included: strengthening certificate-of-need program oversight, reducing bad debt and charity care, increasing transparency in pricing to promote an understanding of the actual costs of care, improving medical malpractice insurance review, limiting needless capital investment by the health care community, capping hospital margins at roughly three percent, promoting the use of underused facilities around the state for non-emergency, outpatient procedures, and placing limitations on insurance premium growth. ${ }^{69}$ The Maine plan was financially supported by individual and employer contributions, an upfront payment by the state of fifty-three million dollars, and is sustained through the use of a unique and controversial savings offset payment ("SOP"). The SOP is based on a complex factorial analysis that is itself based on an aggregate measurable savings largely determined by the revenue reduction spent on uncompensated care. ${ }^{70}$ Essentially this offset adds a two percent surcharge to all health care insurance gross premium revenues that exceed four percent. ${ }^{71}$.

Central to the Dirigo Health Plan was the creation of a public-private venture providing health coverage plans administered by a private insurer, which offers both low and high deductible plans focused on high-quality, preventive care. ${ }^{72}$ The plan is an option for employers with less than fifty employees, as well as those who are self-employed, or individuals up to 200\% FPL. Employ-

66. An Act to Provide Health Insurance to Small Businesses and Individuals to Control Health Care Costs, ME. Rev. Stat. ANN, tit. 24-A, § 6901-6971 (2003). See also Maine.gov., http://www.dirigohealth.maine.gov/dhsp01d.html (last visited Apr. 20, 2008).

67. See Maine.gov., Dirigo Health http://www.dirigohealth.maine.gov/ (last visited Apr. 20, 2008).

68. Id. 2008).

69. See Maine.gov, http://www.dirigohealth.maine.gov/dhlp04.html (last visited Apr. 20,

70. See Savings Offset Payment Q \&A, http://www.dirigohealth.com/SOPQA revised.pdf (providing a detailed discussion of the offset plan).

71. ME. REv. STAT. ANN, tit. 24-A, § 6901-6971 (2003). See also Maine.gov.,http:// www.dirigohealth.maine.gov/dhsp01d.html\#savingsoffset (last visited Apr. 20, 2008).

72. See Maine.gov, Dirigo Partners with Nonprofit, Sept. 2007, http://www.dirigo health.maine.gov/dhlp07.html (last visited Apr. 20, 2008). 
ers are required to pay a portion of the monthly premium for their employees (up to sixty percent of the premium) whereas self-employed individuals and those without insurance pay a premium based on a household income slidingscale.

The Maine program has only enrolled about 28,000 individuals in 2007 and has been met with several challenges. The SOP noted above sustained a court challenge in which the surcharge was upheld as lawful. ${ }^{73}$ Also, as the Dirigo Choice Program has been a voluntary program, Maine citizens have been slow to sign up. Small businesses and individuals have complained that the costs remain too high and that the use of a single insurer has limited options especially in rural parts of the state. Although Governor Baldacci was able to sign legislation requiring Maine's program to self-insure in an effort to promote individual and small business coverage, other initiatives were left on the table for future consideration. The legislature remains interested in passing the following measures: a conversion of SOP to a surcharge on hospital bills, funding for increased primary care services, increased incentives for individuals who choose healthy lifestyle choices, enhancement of care quality measures, and a premium tax on insurers to fund new coverage.

\section{Vermont-Catamount Health}

In May 2006, Vermont legislators and Governor Jim Douglas enacted a voluntary universal plan to control rising costs and help cover 69,000 uninsured citizens. ${ }^{74}$ The Catamount Health Plan provides Vermont residents who are at or below $300 \%$ FPL, the opportunity to purchase subsidized insurance provided by two commercial insurance companies. ${ }^{75}$ In addition to the Catamount Health option, the plan also provides sliding-scale subsidies for those who are employed, or where the employer offers no coverage or limited coverage for either hospital or doctors services. To qualify for subsidies to the employersponsored insurance, the individual must have an annual household income at or below $300 \%$ FPL. $^{76}$ For those who have no insurance, and who are over $300 \%$ FPL, they can participate in the plan and must pay premiums based on a sliding-scale of household income. In order to be eligible for one of the plans, an individual must have been without health insurance for twelve months. Other incentives require the benefits offered by the Catamount Plan to be aligned

73. See Maine Ass'n of Health Plans v. Superintendent of Ins., 923 A.2d 918 (Me. 2007); see also http://www.dirigohealth.com/opp_meahp_mot3_dha.pdf. (The Maine court system again denied the Maine Health Association a third challenge to the validity of the SOP for 2008).

74. 2006 VT. ACTS \& Resolves 191, An Act Relating to Health Care Affordability for Vermonters. See also 2006 VT. Acts \& RESOLVES 190, An Act Relating to Catamount Health.

75. Id. See also Health Care Reform Legislation, http://hcr.vermont.gov/health_care reform_legislation (last visited Apr. 26, 2008).

76. 2006 Health Care Reform Initiatives, http://www.leg.state.vt.us/HealthCare/2006 Health_Care_Constituent_Information_Sheet.htm (last visited Apr. 20, 2008). 
or on par with similar health insurance plans offered in the open market. At minimum, the plans must cover primary care treatment, immunizations, care for chronic health conditions, and hospital services. Although there is a deductible for hospital services, there is no deductible requirement for primary care services or care related to chronic health conditions.

The Vermont Plan is funded by a combination of an 1115 waiver and a progressive tax on tobacco products, including an $\varnothing .80$ per pack cigarette tax. ${ }^{77}$ Employers, who do not provide insurance coverage for employees, must pay a $\$ 365$ yearly surcharge per employee not covered. ${ }^{78}$ Participation in the program is voluntary, but if ninety-six percent of all Vermont citizens are not enrolled by 2010, the legislature will consider a mandate requiring all Vermonters to enroll. Last year, Centers for Medicare and Medicaid ("CMS") agreed to provide federal support for premium assistance up to $200 \%$ FPL which will help the state expand coverage. Other key aspects of the plan include the following: incentives to decrease insurance rates for those who participate in wellness programs, a new program to provide loan relief to attract health care providers to the state, additional programs to increase quality hospital care by minimizing medical errors, and incentives to increase the use of advanced directives to encourage organ donation. Vermont's plan also provides for a regular review of health care cost reductions that will in turn be passed on in savings to Vermont citizens who participate in traditional employer-based insurance plans. Since October 2007, the Vermont plan has enrolled over 700 individuals.

\section{B. Other Promising State Initiatives}

There are other health reform initiatives that have made their way to state legislatures around the country. ${ }^{79}$ While an exhaustive list of all initiatives is beyond the scope of this Note, the more promising aspects of comprehensive state initiatives are presented for discussion here. ${ }^{80}$

\section{California}

California has been locked in a health reform battle that continues to rage. While California's plan has had several setbacks since Governor Schwarzenegger's reform announcement in January 2007, the California effort remains one of the more intriguing proposals on the table, given the totality of the package proposed and the fact that 6.8 million individuals are uninsured in the state.

77. Id.

78. Id.

79. See Nat'l Conf. of State Legislatures, Health Reform Bills, http://www.ncsl. org/programs/health/universalhealth2007.htm (last visited Apr. 20, 2008).

80. Id. Within the next year, the states of Washington, Oregon, Illinois, Wisconsin, South Dakota, Iowa, Connecticut, Kansas, Minnesota, New York, and Virginia will debate major reforms proposals within their respective legislatures. 
Unfortunately, the recent proposal, the Health Care Security and Reduction Act, was killed in Senate committee as it was deemed too expensive. ${ }^{81}$ California's proposal is worth discussing, however, because the passage would certainly raise the stature of the health reform debate as it would represent the largest expansion of health care coverage since the enactment of the federal Medicare and Medicaid programs. The plans currently under consideration would cover 3.6 to 5.1 million of the uninsured including most children. ${ }^{82}$

Under the most recent legislative proposal, an individual mandate would be instituted. Individuals with incomes under $250 \%$ FPL, whose premiums exceed five percent of their income, would be exempt from the mandate. Children up to $300 \%$ FPL would be eligible for any subsidies offered by the state. For those with incomes less than $250 \%$ FPL, the state would subsidize coverage, and for those under $150 \%$ FPL no premiums would be charged. Workers at $250-400 \%$ FPL, who would not otherwise qualify for subsidized coverage, and whose premiums exceed five percent of family income, would receive a tax credit to help offset costs. The California program's proposed financing includes a variety of sources including: an employer contribution of $1-6.5 \%$ for employees not covered (based on the size of the overall payroll); county governments would be expected to contribute up to $\$ 1$ billion to cover costs; tobacco taxes would be raised up to $\$ 1.75$ per pack; and hospitals would pay four percent of revenue to a state-controlled fund. In addition, it is estimated four billion dollars in federal Medicaid funds will be needed to cover the plan. ${ }^{83}$ The state plan also calls for additional features including: 1) use of Section 125 cafeteria plans and the use of health savings accounts by employers; 2) a goal of $100 \%$ connectivity for electronic health data in ten years; 3 ) designation of the "Managed Risk Medical Insurance Board," that would determine coverage and advise on other health-related program matters; 4 ) impose an $85 \%$ medical loss on health plans; and 5) would require health insurance carriers and plans to guarantee coverage for anyone who is under the mandate even with a preexisting condition.

In the end, a Senate committee financial analysis found that the forecasted premium of $\$ 250$ (based on the state's $\$ 187$ Medicaid premium) would instead cost $\$ 300$ causing a $\$ 3.9$ billion dollar shortfall versus the $\$ 2.7$ billion surplus projected by $2015 .^{84}$ Given the fact that California is facing a $\$ 14.5$ billion budget deficit by 2009 , it's not surprising that the measure died in committee. Even so, the sponsors and Governor Schwarzenegger remain committed to reel-

81. See Doug Trapp, Health System Reform Stumbles in California, AMEDNEws.COM, February 18, 2008, http://www.ama-assn.org/amednews/2008/02/18/gvsa0218.htm (last visited Apr. 20, 2008).

82. FAQ About ABX1 1 (Nunez and Perata), http://calhealthreform.org/content/view/63 (last visited Apr. 20, 2008).

83. Health Care Security and Cost Reduction Act, A.B. No. 1 (1 st Ex. sess.) (Ca. 2007).

84. See Trapp, supra note 81 . 
ing in California's rising health costs and getting a health reform package passed.

\section{Maryland}

The Maryland legislature passed the Maryland Fair Share Health Care Fund Act (the "Act") in 2006. ${ }^{85}$ Maryland has the highest per capita income in the country and a lower than average number of uninsured residents, numbering $97,000{ }^{86}$ Although the Act was passed in the legislature, it was not enacted. ${ }^{87}$ Maryland's statute, by intentional design, was drafted to require large employers to pay for insurance for their employees with the hope of expanding coverage to many of the working uninsured. The outcome was that one large company, Wal-Mart, was ultimately singled-out to provide coverage for their employees. What has become known as the "Wal-Mart law," required that all non-governmental employers with 10,000 or more employees provide health care coverage. ${ }^{88}$

The Act required that for-profit employers spend an amount equal to at least eight percent of the total wages paid to its Maryland employees on health insurance costs for those employees. When a covered employer failed to spend the required amount on health insurance, the Act obligated the employer to pay to the Maryland Fair Share Health Care Fund (the "Fund") the difference between the employer's actual health insurance outlays and the employer's statutorily mandated health insurance payments. The Fund, in turn, would be used to finance Maryland's Medicaid program for low-income residents. Further, the Act did not allow employers to deduct from their taxes the required payments for their employee's wages.

On November 19, 2007, Maryland moved forward with other health reform initiatives under the Working Families and Small Business Health Coverage Act ("Maryland Act") that is predicted to cover 100,000 of the uninsured. ${ }^{89}$ The Maryland Act is funded through various mechanisms which include: general funds, lottery revenue, money shifted from the state's high-risk pool fund, and hospital uncompensated care savings. The Maryland Act offers subsidies to small employers with two to nine employees if the employer incorporates a wellness plan and allows for Section 125 cafeteria plans. Other as-

85. MD. CODE. ANN., LAB. \& EMPL. § 8.5-101 (2007).

86. Thomas R. Oliver, Holding Back the Tide: Policies To Preserve and Reconstruct Health Care Insurance Coverage in Maryland, 29 J. HEALTH POL'Y \& L. 203, 204-05 (2004).

87. MD. CODE. ANN., LAB. \& EMPL. § 8.5-101 (2007) (Maryland House Bill 97 introduced Jan. 12, 2006).

88. Edward A. Zelinsky, Maryland's "Wal-Mart" Act: Policy and Preemption, 28 CARDOZO L. REV. 847, 848-50 (2006) (outlining the statute provisions eventually struck down under ERISA preemption); see also Retail Indus. Leaders v. Fielder, 475 F.3d 180 (4th Cir. 2007) (upholding the trial court determination of the ERISA preemption).

89. Working Families and Small Business Health Coverage Act, S.B. 6, 2007 leg., 424th Sess., 1st Spec. Sess., (Md. 2007). 
pects of the Maryland Act included: increasing the age by which dependents could be covered to age twenty-five; establishing the Health Quality and Cost Council; increasing funding for IT initiatives and; providing an expansion of Medicaid eligibility of up to $116 \%$ FPL for poor adults who are parents or individuals who serve as the primary caretaker for a dependent child living at home. $^{90}$

\section{Pennsylvania}

Governor Ed Rendell put forth the "Cover all Pennsylvanians" plan ("CAP") in 2007 to focus on providing coverage options for small businesses and the 767,000 citizens who are uninsured. ${ }^{91}$ Already, Pennsylvania passed the "Cover All Kids" program in 2006 receiving additional federal funding to subsidize premiums for children living in families below $300 \%$ FPL. Currently the Pennsylvania legislature is close to passing the "Pennsylvania Access to Basic Care," ("PAABC") initiative which would increase coverage to the uninsured and would help pay for physician medical malpractice coverage. ${ }^{92}$ The PAABC closely follows Governor Rendell's larger CAP plan introduced last year. If passed, the PAABC will likely be provided through various private market insurance products. Individuals who earn less then $300 \%$ FPL would receive subsidies based on income to pay for monthly premiums which range from forty dollars per month for those at $150-175 \%$ FPL, to fifty dollars per month for those within 175-200 \% FPL. Those at 200-300\% FPL will be responsible to pay the full amount minus an employer contribution which is predicted to be about $\$ 280$ per month. Businesses with fewer than fifty employees who have employees that earn less the state's annual wage would qualify. Businesses qualification would also be required to enroll at least seventy-five percent of all employees and pay up to fifty percent of the employees' premium. The cost would vary but is predicted to not be more than $\$ 130$ per worker, per month. The plan would be paid for through increased federal funds, a "fair share" contribution by non-participating employers, and an increased cigarette tax.

90. See SB6- Summary OF Working Families AND SMAll Business Health COVERAGE ACT, available at $\mathrm{http}: / / \mathrm{mlis}$. state.md.us/Other/Fiscal_Briefings_and_Reports/2007_Summary_ SB6.pdf.

91. See Rx for Pennsylvania, http://www.rxforpa.com/ (last visited Apr. 20, 2008) (the site provides an overview of Governor Rendell's plan).

92. Pennsylvania Access to Basic Care, S.B. 1137, Gen. Assem., Reg. Sess. (Pa. 2007). The Pennsylvania plan offers the following: provides more than 270,000 uninsured working Pennsylvanians access to basic health care; makes $\$ 42$ million available for grants to small business employers who are already providing health-care coverage to their employees; assists doctors by continuing to help pay for medical malpractice insurance premiums; lowers the cost of uncompensated care for hospitals ( $\$ 1.4$ billion a year); and adds funding to every insurance premium to lower premium costs. See also PA ABC Highlights, http://www.hacd.net/budget/ 200809/documents/PA\%20ABC\%20Highlights.pdf. 
The PAABC plan represents a significant step forward and builds upon other important measures passed by Pennsylvania in 2007 which included: seed money for new federally qualified health centers, a comprehensive hospital infection control law, wellness mobiles, and expanding the scope of practice for nurse practitioners to be able to perform more primary care functions. If passed, Pennsylvania's plan will mark the largest movement in covering the uninsured since the introduction of Massachusetts' plan and will mark a significant step forward in the reform movement.

\section{Indiana}

In January, 2008, the Healthy Indiana Plan ("HIP") began enrolling participants into the state's new health coverage program signed into law in July, 2007. Indiana has approximately 560,000 chronically uninsured, and the HIP plan is designed to cover 130,000 of the uninsured. ${ }^{93}$ Indiana's plan was predominantly financed through a 1115 waiver and a $\not .44$ cent increase in the cigarette tax that is estimated to generate approximately $\$ 145$ million in annual revenue. Individuals who have personal income up to $200 \% \mathrm{FPL}$, who are aged eighteen through sixty-four, are U.S. citizens, and have been uninsured for at least six months are eligible for HIP. ${ }^{94}$ The Indiana plan has gained attention through the use of a health savings account model. The deductible for the plan is $\$ 1100$ of which the premium payment is paid through a state-subsidized personal wellness responsibility account ("POWER"). The POWER account contains the monthly contributions made by participants, which is based on a sliding-scale of the individual's income. The total individual contribution starts at two percent and cannot exceed more then five percent gross family income. In addition, participants are given pre-deductible $\$ 500$ free preventive care as an incentive to engage in primary care. Any funds not used by the end of the year roll over to reduce the individual or family's obligation in the next year. In order to roll over the state's portion of the contribution to the POWER account, the individual must engage in the pre-deductible preventive care services. If the preventive care is not used, the state's contribution does not roll over and will be returned to the state. The program provides a lifetime benefit of $\$ 1,000,000$ with the annual benefit not to exceed $\$ 300,000$. Under the Indiana plan, coverage includes: inpatient and outpatient services, mental health treatment, chronic disease management, medications, home health services, and diagnostic testing. While dental and vision are not covered, there is an optional plan available to cover these services.

93. Healthy Indiana Plan Overview: General Training, http://www.state.in.us/fssa/files/ FINAL-_HIP_General_Training_Powerpoint.pdf.

94. IN.Gov, Healthy Indiana Plan, http://www.in.gov/fssa/hip/ (last visited Apr. 26, 2008). 


\section{New Mexico}

New Mexico's Governor unveiled the state's "Health Solutions" plan in October, 2007. It is designed to provide all New Mexicans with health insurance coverage. $^{95}$ The plan calls for employers to contribute to a central fund, with employers receiving a dollar for dollar offset if they are already providing contributions for their employees' health insurance. Other major parts of the plan include: increasing the medical loss ratio for insurers to $85 \%$; guaranteed issue of health insurance regardless of pre-existing condition; and a moratorium on new insurance benefits through 2010. In addition, the New Mexico plan calls for use of health information technology to manage claims and share patient data across provider sites and creates an over-arching governmental authority to manage the state plan that will have accountability for all policy issues.

\section{FUNDING ANALYSIS- HOW IS HEALTH REFORM BEING FINANCED?}

\section{A. Medicaid}

A constellation of funding methods will be necessary to enact, administer, and sustain the wave of new health care reform. As states struggle to creatively keep their budgets balanced, the current reform initiatives hint at interesting, but predictable financing trends. While review of every funding source or stakeholder burden is beyond the boundaries of this discussion, the new plans demonstrate a strong reliance on the following: Medicaid waivers, highly structured employer and employee mandates, and inventive taxation schemes.

Medicaid is an expensive piece of the financing pie for every state, as total Medicaid costs reached over $\$ 315$ billion of expenditures in the United States for 2006. ${ }^{96}$ The average state Medicaid enrollment is around fourteen percent, with many clients in these systems having disabilities and other serious health problems that are expensive to treat. ${ }^{97}$ With Medicaid playing such a significant role in financing health care for the poor, it is almost certain that the federal government will continue to provide some level of support that will leverage federal dollars for health coverage expansion. With a growing federal budget deficit, and with states suffering from a recession and economic turmoil, many states are leery of leveraging more Medicaid dollars as the federal gov-

95. Health Solutions New MeXico: Affordable, AcCessible \& Accountable (2007), available at $\mathrm{http} / / / \mathrm{www} . \mathrm{hsd} . s t a t e . n m . u s / \mathrm{mad} / \mathrm{pdf}$ _files/salud_rfp/HealthSOLUTIONS

NM_Exec_Prop_10-25-07.pdf.

96. KAISER FAM. FOUND., statehealthfacts.org, http://www.statehealthfacts.org/ profileind.jsp?ind $=177 \&$ cat $=4 \&$ rgn $=1$ (last visited Apr. 20, 2008).

97. Kaiser Fam. Found., State Medicaid Facts Sheet for Indiana and United STATES, http://www.kff.org/mfs/medicaid.jsp?r1=IN\&r2=US (last visited Apr. 20, 2008). 
ernment threatens additional Medicaid cut-backs. ${ }^{98}$ States, however, have decided to implement strategies that use federal dollars in the short-term as a means to get their new initiatives off the ground while seeking alternatives for sustained funding that does not involve increasing federal support. Many hope that savings will be realized from the reform packages implemented in the near term which will provide a return on investment in a few years providing an offset that will decrease the reliance on future federal support. In addition, some states, such as Indiana, are trying to find general funds elsewhere to minimize their commitment to matching Medicaid dollars through the use of creative taxes and patient cost-sharing. As previously discussed in the plans above, Medicaid expansion, whatever its form or amount (as noted in the DRA discussion), will be critical to the short-term funding of health care reform initiatives around the country.

Medicaid waivers gained popularity under the Clinton administration as requirements were loosened to encourage more states to use the waivers to attempt new health care initiatives. ${ }^{99}$ As previously discussed, popular in the current round of reform have been the use of 1115 waivers that created under the Social Security Act. ${ }^{100}$ The 1115 waivers provide financial funding for states to experiment with health care delivery models that in many cases expand coverage to individuals who do not qualify for traditional Medicaid. As evidenced with the Vermont and Massachusetts plans, 1115 waivers have been critical to funding new initiatives; Massachusetts leveraged $\$ 385$ million over three years and Vermont $\$ 135$ million over five years with the assistance of waivers. ${ }^{101}$ While 1115 waivers are helpful in funding new initiatives, waiver money is available only for a specified time with no guarantee of additional waiver money offset in the future. Medicaid 1115 demonstration waivers make sense for states that need upfront capital to implement a program before realized savings can be reinvested back into the subsidized health plan. Medicaid waiver expansion allows states the flexibility they need to tailor plans and coverage unique to their populations, health demographics, and geographic constraints.

\section{B. Mandated Employer and Consumer Coverage}

Consumer and employer mandated participation in some form is a feature that will likely be utilized by most states seeking to instill ownership and partici-

98. The DRA will institute $\$ 11$ billion in Medicaid cuts over five years with additional Medicaid cuts also being considered by Congress.

99. Eleanor D. Kinney, Clearing the Way for an Effective Federal-State Partnership in Health Reform, 32 U. MICH. J.L. REFORM 899, 911 (1999) (describing how President Clinton championed 1115 waivers to help spur health reform at the state level).

100. Public Welfare Amendment of 1962, Pub. L. No. 87-543, sec. 122, § 1115, 76 Stat. 172, 192 (amending Social Security Act) (codified as amended at 42 U.S.C. $§ 1315$ (1994)).

101. See WALDMAN, supra note 58; see also 2006 Health Care Reform Initiatives (2006), http://www.leg.state.vt.us/HealthCare/2006_Health_Care_Constituent_Information _Sheet.htm (last visited Apr. 20, 2008). 
pation in the reform process. Success, however, may be limited if the mandates are not married with affordable choices for consumers that provide reasonable coverage. While mandates create immediate opportunities to expand coverage, states must proceed with caution in how the mandates are structured in order to ensure that citizens and businesses are not priced out of the process.

Employers have traditionally provided health insurance coverage, but have often done so with tax subsidies that offset their out-of-pocket costs. ${ }^{102}$ States realize that mandating employer coverage may be an easier conditional requirement given the historical model of employers providing health insurance to employees. States must be careful, however, not to ask employers to shoulder too much of the health care expense. In particular, small and medium-sized businesses may become disproportionately burdened with additional costshifting, impeding their ability to grow and remain competitive. ${ }^{103}$ States are mindful of the economic ramifications of stretching businesses too thin, but current reform efforts reveal that states are relying on employers to pay their fair share as a partner in reform. Although cost savings for employers may be difficult to come by over the short-term, many states are hoping that long-term commitments from employers to the reform process- especially with smaller companies- will ultimately mean costs savings for employers and a healthier and more productive work force.

On the consumer side, mandated plans actually create many of the same potential financial problems as noted previously with employers. While mandating health coverage is an easy way to achieve "universal care," if premiums and costs remain too high and if there is no effort to create health plan coverage that fits all socioeconomic classes, the mandate will create a false safety net where many are left without care and penalized for not being able to participate in the state-sponsored plans. To some extent, this has proven to be the case in Massachusetts, which is currently the only state to mandate coverage for all of its citizens. For example, when the Massachusetts state insurance committee met to review and negotiate the plan premiums, the average premium price was calculated to be $\$ 380$ per month. This premium price, almost double the predicted \$200 per month, is beyond the reach of many intended beneficiaries. ${ }^{104}$ Some fear these increases in required payment will lead to court challenges and public protest that may ultimately doom the program.

102. Carolyn V. Juarez, Liberty, Justice, and Insurance For All: Re-Imagining the Employment-based Health Insurance System, 37 U. MICH. J.L. REFORM 881, 886-87 (2004) (reporting that employers are given tax incentives that approach $\$ 100$ billion, creating a default system where the federal government is essentially already paying half of current health insurance premiums).

103. Id. at $887-89$.

104. Alice Dembner, Sticker Shock for State Care Plan, Boston.com, Jan. 20, 2007, http://www.boston.com/news/local/massachusetts/articles/2007/01/20/sticker_shock_for_state_c are_plan/ (last visited Apr. 20, 2008). 


\section{State Taxing Schemes}

Covering the high costs of health care reform has led to creative taxation schemes that underpin most of the current reform plans. Without question, additional taxation beyond the simple redistribution of general state revenue will be needed to cover what are, not surprisingly, very expensive initiatives. As states scurry to find funding alternatives to minimize pulling additional dollars from their general funds or leveraging additional Medicaid dollars, three taxing schemes have emerged as possible candidates to be replicated in other states: 1) "sin" taxes or tobacco taxes; 2) provider and insurer taxes; and 3) employer payroll taxes or "pay-or-play" contributions.

\section{Sin and Tobacco Taxes}

The easy target of cigarette taxes is gaining popularity as a way to generate income for health reform given the strong association of tobacco products to health problems and disease. The average state tax is now at one dollar per pack with the range from a low of $\phi .07$ in South Carolina, to a high of \$2.54 in New Jersey ${ }^{105}$ Every major state proposal thus far contains some form of a tax on tobacco products which in some cases is the major source of funding of the health reform plans. While other taxes have been used with respect to alcohol, there are some consumer groups advocating taxes on soft drinks or even fastfood, but there must be more interest from state legislatures if such taxes are to be formulated.

\section{Provider and Insurer Taxes}

Second, and more controversial, are tax proposals that will be levied against major health care stakeholders - specifically the insurance industry, hospitals, and doctors. While these taxes will likely be challenged, the new wave of reform has given states political courage to challenge the traditional heavy-weights of the health care system. In Maine, for example, the savings offset plan tax on health insurance transactions was designed to create an incentive for the insurance industry to participate in reform and to avoid the costshifting of uncompensated care in the form of increasing premiums to those with insurance. Maine hopes that over time the tax will actually prevent losses to insurance companies by providing additional savings for all stakeholders realized by the state's funding of the uninsured. Maine further justified the tax as the insurance companies were given the contract to administer the state health

105. American Lung Association, Good News:Smoke-free Workplace Laws, Cigarette Taxes Increase, SEARCHLUNG USA, Jan. 9, 2007, http://www.lungusa.org/site/apps/s/ content.asp? $c=$ dvLUK9O0E $\& b=34706 \& c t=3383613$ (last visited Apr. 20, 2008). 
plan and are now partners with the state in driving the economic change in health reform.

Governor Schwarzenegger's California proposal utilized a similar argument by initially proposing a plan to tax doctors and hospitals. Schwarzenegger had justified the health provider tax by stating he would use the levy to finance California's insurance subsidization plan which would then offset uncompensated losses to hospitals and providers. New Jersey, however, did successfully adopt a provider tax to fund their uncompensated fund by levying a 3.5 percent tax on privately held ambulatory surgical centers and a six percent tax on gross receipts on physicians performing cosmetic procedures. ${ }^{106}$ While the provider tax trend has not played out in many state legislatures, it is certainly an option being discussed, especially in states where certificate-of-need laws are not in force.

\section{Employer Taxes}

Employer payroll taxes, and "pay-or-play" contributions, have been widely considered for those who refuse to provide coverage for their employees. Adding employer payroll taxes seem an easy target to generate revenue, but as has been the case and will be discussed below, many taxes designed as an employer mandated payment for health care fall under the preemption umbrella of the Employee Retirement Income Security Act ("ERISA"). As more states consider employer mandates, Congress may be forced to pass ERISA revisions or alternatively, the courts may find ERISA does not apply to health reform efforts. But until then, levying an employer tax certainly invites political and legal challenges. It could be the case, however, that Congress increases the option for federal payroll taxes as already provided for with Medicare coverage. Given the size and scope of Medicare and the payroll tax already in place, expansion of this program may be the low-hanging fruit visited first by the new President in 2009 as a means to expand care to more individuals under a federal plan.

\section{Health Savings Accounts and High Deductible Health Plans}

Increasingly, many employers and states are considering the use of HSAs in conjunction with high deductible health plans ("HDHP") as a means to decrease expenses by sharing costs with participants. These types of plans have been touted by the Bush administration and other political conservatives ${ }^{107}$ as a

106. N.J. StaT. ANN. § 53:3125 (West 2004) (six percent cosmetic levy); N.J. STAT. ANN. $\S 54: 3127$ (West 2004) (3.5 percent surgery clinic levy). See also Robert E. Hurley et al., $A$ Widening Rift in Access and Quality: Growing Evidence of Economic Disparities, HEALTH AFF., Web Posting Dec. 6, 2005, http://content.healthaffairs.org/cgi/content/full/hlthaff. w5.566/DC1 (last visited Apr. 20, 2008).

107. Republican presidential hopeful John McCain has championed HSAs as a means to 
strategy to curb increasing health care costs. HSAs and HDHPs have yet to significantly reach the mainstream, but are predicted to account for twenty-four percent of the future health insurance market by $2010 .^{108}$ The combination of HDHPs with HSAs has thus far been met with mixed reviews. While there is hope that a positive economic impact will result in decreasing health care utilization, HSAs have not been shown to help those in the uninsured ranks. ${ }^{109}$ Further, the theory behind HDHPs is to incentivize the wise use of health care to prevent unnecessary over-utilization of health care goods and services that some believe has historically been fueled by traditional lower deductible plans. ${ }^{110}$ In reality, what appears to be occurring is that HDHPs are curbing costs at the expense of sacrificing health care quality and access as many clients using HDHPs are putting off care due to the increased deductible and associated out-of-pocket expenditures. ${ }^{111}$ These combination plans will likely continue be a common reform component, but their success will hinge upon whether participants feel they can afford the increased out-of-pocket costs that these types of plans often require. States must find ways to maximize subsidization of HDHPs with the use of HSAs in order to incentivize consumers to seek health care services, especially preventive care. Reform efforts, as witnessed in Indiana, seem to understand this concern and have addressed the issue by doing the following: making the HDHP deductible subsidy tied to a cigarette tax, limiting participant investment to no more than five percent of gross total family income, and including a set amount of free preventive health care that is subsidized by the state. ${ }^{112}$

Although this section focuses more on the taxation schemes being utilized by the states to generate revenue, it should be noted as part of this discussion that there have been federal proposals under the Bush administration to provide tax breaks to incentivize consumers to purchase health insurance that presents a viable alternative to expanding coverage. As discussed previously, President Bush has been proposing a standard tax deduction of $\$ 15,000$ for families and $\$ 7500$ for single Americans whether they have employer-provided health coverage or they purchase health coverage independently. ${ }^{113}$ The tax credit fits in as part of the President's plan to shift accountability to consumers by incentiv-

control health care costs and has featured HSA use as part of his health care plan for America. See Johnmccain.com, http://www.johnmccain.com/Informing/Issues/19ba2flc-c03f-4ac2-8cd55cf2edb527cf.htm (last visited Apr. 26, 2008).

108. Philip Betbeze, The Banks are Coming, Health LEaders Magazene.com, Dec. 14, 2006, http://www.healthleadersmedia.com/view_feature.cfm?content_id=85773 (last visited Apr. 26, 2008).

109. Hoffman \& Tolbert, supra note 36 (reporting that the combination of HDHPs and HSAs work best for those who are wealthier, healthier, or have significant employer contributions to off-set high out-of-pocket costs).

110. Id.

111. Id.

112. See IN.Gov, Healthy Indiana Plan, http://www.in.gov/fssa/hip/ (last visited Apr. 26, 2008).

113. The Whitehouse, Strengthening Health Care, http://www.whitehouse.gov/infocus/ healthcare/ (last visited Apr. 20, 2008). 
izing personal choice and responsibility. Critics of the plan contend that only three to five million of the uninsured will be covered with the tax credit, and that the President's plan does nothing to hold insurance companies accountable to address the spiraling costs of premiums which are often consumers' main obstacle to obtaining coverage. ${ }^{114}$ Tax credits and other federal incentives, however, demonstrate a possible connection that can be made by the federal government, in addition to incentives at the state level, to promote health coverage expansion. The topic of tax credits and other possible federal funding schemes is currently a top issue being discussed among the presidential candidates. $^{115}$

\section{THE STAKEHOLDERS FIGHT BACK}

As major stakeholders like the insurance industry become increasingly targeted as part of the reform efforts, it is not surprising that most will resist the state and/or federal government's attempt to redefine their role in the health care system. Two recent legal actions may signify a precursor to what other states may face in the way of legal challenges to their new initiatives.

\section{A. Insurance Industry}

The insurance industry remains the major player that will not be moved easily from its entrenched position in the health care system. Although most state plans have found a way to include health insurance companies in the reform process, it is clear that reform-minded states are beginning to have a more profound influence on how insurance companies do business. ${ }^{116}$ As a result, insurance companies are testing state plans quickly and vigorously in court. One example of this can be found in a recent lawsuit filed by a major health insurance company, Anthem, in conjunction with state business leaders against the state of Maine. ${ }^{117}$

In Maine Ass'n of Health Plans v. Superintendent of Ins., the insurance industry claimed that Maine's $2.4 \%$ savings offset payment represented an "improper delegation" of the legislature's tax power. ${ }^{118}$ The insurance company

114. See Gardner, supra note 37.

115. See KAISER FAM. Found., 2008 Presidential Candidates Health Care Proposals: Sideby-Side Summary, http://www.health08.org/sidebyside.cfm (last visited Apr. 20, 2008) (Presidential candidates Barack Obama, Hillary Clinton, and John Mc Cain have all proposed either federal tax credits or federal subsidies for individuals and employers to assist with purchasing health insurance. Hillary Clinton is the only candidate proposing an individual mandate).

116. Sharona Hoffman, Unmanaged care: Towards Moral Fairness In Health Care Coverage, 78 IND. L.J. 659, 713-18 (2003). See also Hermer, supra note 13, at 82 (2005).

117. Maine Ass'n of Health Plans v. Superintendent of Ins., 923 A.2d 918 (Me. 2007) (the Maine Supreme Court affirmed the lower court's decision holding that the State's ability to assess the insurance premium adjustment payable by health insurance companies to support the State health plan was legally viable).

118. Id. 
argued that the legislature did not legitimately construct the tax and that the payment therefore fell under the void for vagueness doctrine which made the provision unconstitutional. The court disagreed and ruled in favor of Maine. In the opinion, the court provided a detailed analysis of the offset payment system and held that the offset was an appropriate and legitimate method by which the legislature could redistribute funds to pay for additional health care under the general police power of the state. Regarding the constitutional argument, the judge stated that the universal health care statute was sound, as there was no evidence presented by the insurance company that the Maine Legislature had overstepped its authority in delegating to the Dirigo Health Agency board the ability to calculate the offset. ${ }^{119}$ While this case represents an early challenge in one jurisdiction, the result is nevertheless significant, as the decision represents an early victory for a state seeking to find innovative strategies to create universal health care. The decision also symbolizes a shot across the bows of insurance companies, putting them on notice that states may be gaining more authority to regulate the insurance industry as health care reform efforts continue.

Many in the insurance industry realize reform efforts are here to stay and that the times are rapidly changing regarding provision of health care. ${ }^{120}$ While insurance companies will continue to be a dominant voice at the negotiating table, their participation in the process will be hedged towards warding off reform efforts that shrink their bottom lines. Thus far, the health insurance industry is injecting its "own" ideas that appear to be disguised marketing campaigns, which do not truly offer any unique solutions to the health care crisis. For example, insurance companies have endorsed efforts that include promoting high deductible health plans to capture younger, healthier, uninsured clients, ${ }^{121}$ encouraging higher taxes on cigarettes, service charges on patients for each visit to their health care provider, tax credits, and a payroll levy for employers who do not cover their employees. ${ }^{122}$

With all of the insurance company proposals, there remains the need for more discussion about reigning in premium costs and more discussion about administrative costs paid to the bottom line. Health insurers, however, are being forced to move toward a more lean business model where dramatic shifts in administrative costs and actual health care dollars paid against increasing medi-

119. Id.

120. Juarez, supra note 102 , at $889-90$ (noting insurance companies history of fighting back against reform with high profile campaign and lobbying efforts).

121. Robert Kazel, Wellpoint/Blue Cross Finds Profits in High Deductibles for Young and Healthy, AM. MED. NEws, Jan. 17, 2005. http://www.pnhp.org/news/2005/january/well pointblue cross.php (last visited Apr. 20, 2008) (noting that Wellpoint is exploiting a market niche to increase the company's profit).

122. Lisa Girion, Insurers Have Own Ideas on Coverage, LATIMES.COM, Jan. 22, 2007, http://www.latimes.com/business/la-fi-insure22jan22,1,7202037.story?ctrack=1\&cset=true (last visited Apr. 20, 2008). 
cal-loss ratios are well underway in the marketplace. ${ }^{123}$ With so many individuals having employer-based insurance and by having access to valuable patient health information and provider practice behaviors, the insurance companies are uniquely positioned to continue to play a key role and will still wield much power in the health delivery process. While there is much anti-insurance company sentiment from some advocates engaged in the reform movement, the fact of the matter is that the health insurance system has been in place for so long that it cannot be easily unwound in a few years. There is no doubt that redefining the health insurance company's role in the health care system will require assessing creative options for all stakeholders to see what makes the most economic sense. While public-private initiatives may be a wise move for states with respect to partnering with the insurance industry to provide coverage for services, this collaborative model will likely require walking a fine line between profits and true reform. Both sides must enter the reform process committed to ensuring reasonable costs and coverage for all citizens. States must realize that they have the power to push for change and must ultimately find a way to be collaborative, while still being forceful in challenging health insurers to be more transparent and competitive in their pricing plans.

\section{B. Employers}

Much of the reform debate has focused on alleviating the burden of high health care expenditures on employers. With nearly 250 million individuals still tied to some form of employer-based insurance plan, it seems unlikely that an un-tethering of employer-based insurance will occur any time soon. ${ }^{124}$ States are well aware that as employees opt out of employer-based plans, further stress is placed on the state to create some type of coverage alternative. The question remains, however, whether employer contributions can continue into the foreseeable future as central means to support health insurance coverage. While some larger employers may be in a better financial situation to provide benefits, these same employers have found themselves battling new health reform initiatives. While most employers welcome the addition of health care for their employees, some worry that plans may place them at risk if the plans are not structured properly or create additional financial burdens. Like the insurance industry, employers potentially stand to lose a lot of autonomy as reform efforts

123. Daniel Lee, What's Ailing Wellpoint?, InDIANAPOLIS STAR, Apr. 13, 2008, at D1 (In early 2008 , Wellpoint has faced a year in which money paid on medical claims versus premium revenue (medical-loss ratio) is expected to increase by $2.3 \%$ over the past three years. Although Wellpoint has trimmed its administrative costs down to $14.5 \%$ in 2007 from $16.5 \%$ in 2005 , the company continues to be battered by higher payouts for physician services, oncology care, and neonatal intensive care. As of April 2008, company stock had plummeted in value by $47 \%$ compared to the beginning of 2008).

124. See DeNAVAS-WALT ET AL., supra note 5, at 26 (noting 201.7 million have private insurance and 80.3 million have government-sponsored health insurance). 
evolve, forcing employers to challenge proposals that increase their responsibility to pay for and provide health coverage.

In one noteworthy case, Retail Industry Leaders Ass' $n$ v. James Fielder the large retailer Wal-Mart filed a lawsuit protesting the Maryland health reform package. ${ }^{125}$ As previously discussed, the proposed Maryland statute required for-profit employers with over 10,000 employees who did not provide coverage to pay the equivalent of eight percent of the employees' payroll to cover health care. In this case, Wal-Mart is the only company in Maryland that meets the statutory minimum of 10,000 employees. Wal-Mart contended that the required contribution was preempted by ERISA and also violated the equal protection clause of the United States Constitution. ${ }^{126}$ The court ruled that the eight percent mandate was not a tax per se but did conclude that the Maryland statute was preempted by ERISA and nullified the revenue payment required under the Maryland statute. ${ }^{127}$ The court stated that Wal-Mart could not be forced by Maryland to provide benefits in one manner in their state and then be expected to provide the same benefits in a different manner in other states.

The effect of this case has been to halt the enactment of Maryland's plan that was passed last year. While the intent of this plan was to incentivize employer coverage, it appears to be poorly designed in that it legislatively isolates one large employer. Other states have considered similar employer-mandated "pay-or-play" bills, but it remains to be seen if court decisions like this could impact their efforts moving forward or if it will force states to consider other avenues for integrating employer mandates into their reform plans.

\section{AN UN-INTEGRATED SYSTEM: POLICY CONSIDERATIONS TO KEEP ON THE TABLE}

While there are divergent views on how to fix the health care crisis, many would argue the time is ripe for a nationalized single-payer system. The political will to take this monumental step, however, is lacking and the health care crisis will not be easily fixed by simply implementing a uniform payer under a federal health program. Such a plan would be short-sighted if other policy considerations are not examined as part a comprehensive and meaningful federal reform package. Further, jumping quickly into a federal single-payer system, without a well planned strategy, will be a hard sell to many who still favor incremental reform-just ask Hillary Clinton. As states have recently moved forward in their various plans, several important policy considerations have emerged that make sense during this short-term burst of reform. As the current state plans come into view, it is apparent that state legislators' recognition of a more broad approach to health care reform is required to modernize and update

125. Retail Indus. Leader Ass'n v. Fielder, Civil No. JFM-06-316 (Md. Dist. Ct. 2006),

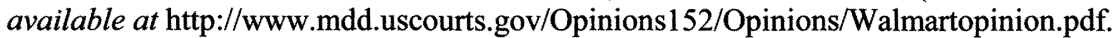

126. Id.

127. Id. 
systems to reach the goals of a cost-effective, efficient, and quality health care delivery system. With the states leading current efforts, it is time for the federal government to take note and pursue a more aggressive stance on reform. Listed below are policy considerations that the federal government might use to work with the states to spur on the innovation needed to succeed in meeting the future health care needs of our country.

\section{A. Information Technology}

One of the most important initiatives that both state and federal governments must support in order to successfully move the health care system forward will be the effective use of information technology ("IT"). Although most other major industries understand the importance of harnessing the transformative powers IT can provide, the health industry has been generally slow to adopt and incorporate IT into the care delivery process on either the provider or consumer end. Investment in health care IT integration has the potential to transform how care is provided, research is conducted, and the manner in which patients and providers are educated and interact with the health care system. The intersection of IT and computer-assisted care has the potential to radically change and influence the way care is provided whether it be IT integration with the doctor operating in a surgery suite, the sharing of lab data with a nurse practitioner in a rural primary care clinic, or having the ability to virtually interact with a patient through their home computer or cell phone. While computer and cell phone applications related to the health care industry are cropping up everywhere, the adoption and use of IT in areas such as tele-health initiatives, quality measurement and tracking, and sharing data across institutions and clinic sites is in many ways only just beginning to be integrated in a meaningful manner in the health care industry. While there are many political, economic, and legal obstacles to overcome when creating a nationwide network of shared patient and health data, the promises of improved patient outcomes, safety, and the efficiency and cost-savings that can be realized from integrating health IT requires a meaningful and sustained government initiative to move IT integration and utilization forward.

\section{Electronic Medical Records and Regional Health Information Organiza- tions: Connecting the Health Information Dots}

As already noted above, although the digital-age is well under way, the U.S. medical community lags behind other industrialized countries in moving from a paper-based medical records system to an electronic medical records ("EMR") system. ${ }^{128}$ Utilizing EMR is a necessary first step to creating a more 
efficient system that will benefit providers and consumers alike, and it has the potential to save as much as eighty-one billion dollars per year in health care costs. ${ }^{129}$ Benefits of EMR include: easy twenty-four hour access to current and accurate patient information, increased safety when reviewing potential drug interactions, improved ability to contact previous providers, confidence that the right information is being shared, increased knowledge of the patient regarding their health, improved potential to reduce patient care errors, and less ordering of needless duplicative tests. ${ }^{130}$ Currently many hospitals and provider clinics are at various stages of adopting EMR platforms, which has created a partially integrated and fragmented information system that frustrates many providers. ${ }^{131}$ This fragmentation has been largely due to competition of various IT vendors which has created a system where the various IT systems fail to "talk" to each other. Successful EMR adoption will require that IT systems and databases be able to communicate in order to realize the full benefits of efficiency. Implementation of EMR, however, will not be without difficulty as overcoming the issues of cost, ease of use for providers and other clinic staff, and implementation across institutions will require coordination of many parallel systems of data collection. ${ }^{132}$

Currently, around the country local health care providers and regional government officials are advocating a more integrated approach to finding a solution to the inability of providers to share health information across institutions. Regional Health Information Organizations ("RHIO"), sometimes referred to locally as Health Information Exchanges ("HIE"), around the country are beginning to set up commonly shared foundational databases designed to improve accessibility and coordination among providers. ${ }^{133}$ The goal of the RHIOs is to try and build a common platform that can be used and integrated into any provider or applicable research network for the purpose of sharing patient and health data. Although in its embryonic stages, HIEs and RHIOs are beginning to take hold around the country, and there are now approximately 100 organizations in various stages of setting up an HIE or operating as part of

no shortage of ideas on how to apply IT into the care process, but attitudes regarding being able to use IT appropriately in addition to the high cost of infrastructure expansion have proven to be difficult for all stakeholders). See also Dena E. Rifkin, Electronic Medical Records: Saving Trees, Saving Lives, 285 JAMA 1764, 1764 (2001).

129. Richard Hillestad et al., Can Electronic Medical Records Transform Health Care? Potential Health Benefits, Savings and Costs, 24 HEALTH AFF. 1103, 1103-117 (2005) (fullscale implementation of EMR will have an immediate impact on chronic disease management and will also have tremendous benefits with respect to patient safety and disease prevention).

130. Thomas Bodenheimer \& Kevin Grumbach, A Spark to Revitalize Primary Health Care?, 290 JAMA 259, 259-64 (2003) (discussing the positive impact for health providers in being able to readily exchange health information).

131. David Gans et al., Medical Groups Adoption of Electronic Health Records and Information, 24 HeLATH AfF. 1323, 1323-33 (2005); see also Ashish K. Jha et al., How Common Are Electronic Health Care Records in the United States? A Summary of the Evidence, 25 HELATH AFF. W496, w496-w505 (2006).

132. See Hillestad et al., supra note 129 , at 1114-15.

133. See generally Julia Adler-Milstein et al., The State of Regional Health Information Organizations: Current Activities and Financing, 27 HELATH AFF. w60, w60-9 (2008). 
a RHIO. ${ }^{134}$ Many of these organizations are still in the planning phases while others have actually agreed to a common platform and shared data set that is being shared. ${ }^{135}$ While financing these projects has proven to be expensive and sustainability remains a real question for some of the newly formed networks, states that are able to support and connect to a centralized database will more quickly realize savings in having a single on-line integrated system that creates a common database for clinicians and other stakeholders. In addition, investment in the health IT infrastructure will drive other industries such as the Life Sciences which will require a completely new business model for building the jobs of the future. Public financing should continue to support the transformation of HIEs and RHIOs into sustainable business models that play key roles in improving the efficiency of the health care system. ${ }^{136}$

In this new era of information technology, patient advocates are concerned that health information could end up in the wrong hands if not properly protected. ${ }^{137}$ The responsibility and the success of a shared patient medical records system will lie with legislators and system users who must insist that every measure be taken to protect the privacy of patient information. Any erosion of public faith on this issue could wreak havoc in trying to build political will for reform in other areas. Further, while strict enforcement of privacy through the Health Insurance Portability and Accountability Act ("HIPAA") ${ }^{138}$ laws must continue; these regulations should not hamper a coordinated effort to accelerate the use of EMR to enhance care and save health care dollars. ${ }^{139}$ The federal government's partnership can play a critical role in ensuring regulations are enforced fairly, but also in a manner that promotes health care innovation.

134. Id. at w63. The study suggests that there are currently around 102 entities operating around the U.S. as a RHIO with approximately thirty-two actually sharing information and approximately twenty organizations conducting more robust networking and data sharing.

135. Id. at w64-5. The study noted that some RHIOs have set up more complex data sets that include the sharing of patient histories, outpatient information, lab results, and medication management data whereas others are more limited in their data sharing, tracking specific disease processes such as one RHIO trying to capture pediatric asthma utilization data.

136. Id. at w65-7. With respect to financing RHIOs are heavily dependent on grants, inkind donations of time, and public financing support. Most RHIOs are new business models and are trying to strategically align themselves in the communities they operate to show their value. Some RHIOs are charging a user fee as a way to increase sustainable funding. Of all the RHIOs identified in the study only eight to twelve RHIOs have sustainable funding in place.

137. Sean McLaughlin, Pandora's Box: Can HIPAA Still Protect Patient Privacy Under a National Health Care Information Network?, 42 GoNZ. L. REV. 29, 37-40, 49-52 (2006) (discussing that a national health information system must have sufficient safeguards in place in order to successfully implement EMR while protecting patient privacy).

138. Health Insurance Portability and Accountability Act of 1996, Pub. L. No. 104-191, 110 Stat. 1936 (codified in scattered sections of 26, 29, and 42 U.S.C.).

139. McLaughlin, supra note 137 , at 60. 


\section{Chronic Disease Management: Getting Control Early}

Chronic disease management for common illnesses such as hypertension and diabetes is another key area states have identified as critical to containing health care costs. ${ }^{140}$ Approximately 1.7 million people die each year as a result of chronic disease. ${ }^{141}$ Estimates indicate that ninety million people in the United States live with a chronic disease, which amounts to seventy-five percent of the annual $\$ 1.4$ trillion health care budget. ${ }^{142}$ The disconnect between reimbursing chronic health care initiatives and poor health outcomes has become an issue not only for clinicians, but also for third party payers that ultimately play a major role in financing care related to chronic diseases. ${ }^{143}$ Recent state reform efforts, as outlined previously with Vermont, demonstrate the recognition that no health care reform effort can be complete without addressing care surrounding chronic health concerns that consume a large amount of state budgets. The success of any state plan will be due in large part to the ability of states to aggressively decrease the economic burden of chronic disease. Chronic disease management will have the most impact where focused on decreasing disease occurrence within the general population while also aiming to improve the health of citizens living with chronic diseases. ${ }^{144}$ As part of their reform efforts, states must be committed to offering plans that feature chronic disease programs tied to education and health promotion. In order to reach the uninsured more quickly, improving chronic care disease care could be achieved by increasing funding to community health clinics and utilizing public health nurses to provide residential follow-up and education needed to increase care compliance.

Further, as discussed above, the integration of IT in coordinating care for those with chronic disease will be crucial to controlling health care costs. In addition to using IT to send patient reminders about appointments and medication changes, IT can be used to design a "virtual care plan" where patients that require intense monitoring can have information from a medical device or other treatment data routed directly into their provider's office. And more importantly, providers can be linked to each other to ensure collaboration is enhanced as part of the patient care plan.

140. See also A Public Health Action Plan to Reduce Heart Disease and Stroke; AN EXECUTIVE SUMMARY, CTR'S FOR DISEASE CONTROL, http://www.cdc.gov/dhdsp/library/ action $\mathrm{plan} / \mathrm{pdfs} /$ action plan short.pdf.

141. Ctr's for Disease Control, Profiling the leading Causes of Death in the UNITED STATES, http://www.cdc.gov/nccdphp/publications/factsheets/ChronicDisease/pdfs/ 00_ChronicDiseaseAllStates.pdf.

142. CTR'S FOR DISEASE CONTROL, COSTS OF Chronic DiSEASE, http://www.cdc.gov/ nccdphp/overview.htm\#2.

143. Jennifer L. Wolff \& Chad Boult, Moving Beyond Round Pegs and Square Holes: Restructuring Medicare to Improve Chronic Care, ANNALS OF INTERNAL MED. 493, 439-45 (2005).

144. Paul A. Nutting et al., Use of Chronic Care Model Elements is Associated With Higher-Quality Care for Diabetes, ANNALS OF FAM. MED. 14, 14-20 (2007). 
Typically, patients (especially those with chronic illnesses) may need access to many different resources to properly treat their individual health needs. Many individuals have chronic conditions, such as mild asthma, which may have only a minimal impact on their daily activities and can be easily managed through routine primary care. Other individuals have multiple or complex chronic conditions such as advanced diabetes or heat disease, that requires extensive care management across many different specialties. Currently when a patient seeks care for multiple problems, such as with a chronic illness, they often receive services with little or no coordination between providers. ${ }^{145} \mathrm{Spe}-$ cialty and primary care providers often administer parallel patient care where there is minimal effort or ability to share information or a treatment plan regarding a common patient. For example, one patient may see doctor A, a specialist, and then see primary care doctor B two weeks later for the same condition, unaware of what doctor A prescribed or what tests were ordered. This lack of communication and coordination leads to many problems including: unnecessary expenditures and administrative waste, repeat of needless procedures, the loss of critical patient information, treatment delays, jeopardizing of patient safety, and complication of on-going treatment plans. This dislocation in care is often driven by many factors such as insurance coverage, provider behavior, institutional boundaries, staffing, or technology availability to gather and exchange data. ${ }^{146}$ Successful and efficient patient outcomes can only be brought about through increased efforts to share patient information between providers, linked by innovative IT programs. These coordinated efforts need to be tied to best practices and clinical outcomes that can be measured and shared across clinic sites as standard treatment plans that define the acceptable level or type of care the patient should receive.

When considering the over-utilization of health care dollars, the first place to examine closely should be right in the provider's office, as doctors directly and indirectly control approximately eighty percent of all clinical costs. ${ }^{147} \mathrm{Al}-$ though the transaction that occurs between provider and patient has a strong cultural and legal history of being sacred and off-limits, this relationship is no longer beyond scrutiny in a climate driven by cost-effective care. One strategy being utilized in the clinical setting to enhance care and control costs is the use of Clinical Practice Guidelines ("CPGs"). CPGs provide a scientific, evidencebased approach to providing care that creates a clinically tested means to address the challenges of providing care that is both superior and cost-effective. ${ }^{148}$ A simple example of the effective use of a CPG could be illustrated in the

145. See George Halvorson, Health CARE Reform Now 211-18 (2007).

146. Id. at 33-57.

147. Stefani Daniels \& Richard Reece, The Business Case for Hospital Case Management, HEALTHLEADER.NEwS, Mar. 1, 2007, http://www.healthleadersmedia.com/viewfeature/ 87605.html (last visited Apr. 20, 2008).

148. Robert Steinbrook, Guidance for Guidelines, 356 NEW ENG. J. MED. 331, 331-33, (2007) (discussing how practice guidelines can enhance care across specialties and create a more cost-effective approach to providing care). 
treatment of a patient with type II diabetes. If a clinician were to consult a treatment guideline, such as the National Guideline Clearinghouse, ${ }^{149}$ the medication choices recommended may provide alternative therapies that are effective and cheaper than the patient's current medical therapy. CPGs ensure that patient treatment plans are benchmarked to specific targets that reflect a standard of care that has been proven with medical evidence to be an effective care strategy. CPGs provide standards that enhance and improve utilization of health care dollars, while at the same time empowering the patient and clinician to work together to choose from many treatment options that can be tailored to meet the individual patient needs without succumbing to "cookbook medicine" or a "one-size-fits-all" approach to health care.

\section{Quality Measurement and Tracking: Excellence in Care Must Drive Re- form}

Quality has become the new mantra for health delivery systems in recent years. New programs such as pay-for-performance ("PFP") payment schedules and the desire by providers to implement evidence-based practices that bring about optimal patient outcomes are driving a major redesign effort in the delivery of care. In addition, all stakeholders in an effort to promote safety, increase efficiency, and contain costs have been looking to define specific quality initiatives as a means to measure both the real economic value and clinical value of the services being provided. As noted above, with the discussion of the exchange patient and health data and the implementation of practice guidelines especially for those with chronic diseases, IT will play a key function in utilizing data systems to capture the pertinent measurement data needed to measure quality. In addition, standards and measurement guidelines will need to be designed in order to create valid measurement tools. Already nationally recognized groups such as the National Committee for Quality Insurance who implement the Healthcare Effectiveness Data and Information Set ("HEDIS") evaluation system, and the Agency for Healthcare Research and Quality ("AHRQ") who provide the Consumer Assessment of Healthcare Providers and Systems ("CAHPS"), have been blazing a trail to obtaining objective quality data sets and tools that have been used to measure a whole host of treatment processes, plans, and health delivery mechanisms. ${ }^{150}$

Further, states engaging in health reform have recognized the importance of placing quality first. For example, the three states that have led comprehensive reform efforts, Massachusetts, Maine, and Vermont have created either quasi-governmental or governmental bodies that have direct accountability for

149. See National Guideline Clearinghouse, http://www.guideline.gov/ (last visited Apr. 26, 2008).

150. See National Committee for Quality Assurance, http://www.ncqa.org/tabid/ 59/Default.aspx (last visited Apr. 26, 2008); see also Agency for Healthcare Research and Quality, https://www.cahps.ahrq.gov/default.asp (last visited Apr. 26, 2008). 
measuring and monitoring quality. Maine has the Quality Forum ("MQF") which grew out of the Dirigo health reform legislation. ${ }^{151}$ The MQF consists of a director that works in concert with an advisory board of providers, consumers and representatives of labor, and other policy agencies. The MQF was designed to foster quality initiatives that promote best clinical practices and track patient data that can show what treatments have the greatest impact on care. The program also links patients to education programs to raise awareness about preventive care and the signs of disease to promote early primary intervention and healthy lifestyle choices. Likewise, in 2006, Massachusetts developed the Health Care Quality and Cost Council ("HCQCC"). ${ }^{152}$ The HCQCC was charged by the Legislature to oversee actions to improve the health outcomes and utilization of health care dollars. The HCQCC recently defined a comprehensive six part plan aimed at: 1) reducing the cost of health care to no more than the unadjusted growth of GDP; 2) ensuring patient safety and effectiveness of care; 3) improving screening and management for chronic disease management; 4) developing and implementing data collection and measurements to improve quality especially in those areas that are underperforming in quality and end-of-life care; 5) eliminating racial and ethnic disparities; and 6) promoting quality through transparency. ${ }^{153}$ These health reform quality initiatives represent the gold standard other states should follow in ensuring a culture and environment of quality is established where optimal patient outcomes is the goal for both providers and patients and where achieving quality and costeffectiveness is maximized and rewarded.

\section{B. Revisiting the Core Infrastructure: Patient Utilization and Provider Capacity}

\section{The Construction Re-Explosion and the Subsequent Reverberations}

During the 1990s hospital bed growth slowed, but with the retirement of baby boomers and the renewed competition for market share, the race to build new facilities is back on. ${ }^{154}$ Also contributing to the construction craze has been the evolution of specialty hospitals and joint ventures. ${ }^{155}$ While many 2008).

151. Maine Quality Forum, http://www.mainequalityforum.gov/ (last visited Apr. 26,

152. Massachusetts Health Care Quality and Cost Council, http://www.mass.gov/ ?pageID=hqcchomepage $\& \mathrm{~L}=1 \& \mathrm{~L} 0=$ Home\&sid=Ihqcc (last visited Apr. 26, 2008).

153. RECOMMENDATIONS FOR IMPROVING HEALTH CARE QUALITY, CONTAINING HEALTH Care Costs, and Reducing Racial and Ethnic Disparities in Health Care, http://www. mass.gov/lhqce/docs/fs_lead_recommendations.pdf. (2003).

154. David Shactman et al., The Outlook for Hospital Spending, 22 Health AfF. 12, 12-25

155. See Lola Butcher, Too Much Construction?, HeAlthleaders MAgazene, Oct. 2006, http://www.healthleadersmedia.com/magazine/view_magazine_feature.cfm?content_id $=84250$ 
question whether the health care sector can simultaneously continue to build new hospitals in the face of escalating costs, others see the new construction as a legitimate response to changes in the health care market. Regardless of the perspective, it remains to be seen whether the new explosion of construction is truly adding value to the health care system or simply providing another costshift with smaller community hospitals bearing the brunt of caring for the uninsured as hospital systems that are better economically positioned move to the insurance-rich suburbs. With many hospitals struggling to keep beds filled, some states, as part of their reform efforts have questioned whether building new facilities is the right answer. Although average daily occupancy is difficult to track, the Center for Disease Control has placed a national average daily census for hospitals at approximately sixty percent. ${ }^{156}$ As hospitals stretch to keep profitable occupancy rates, states have made reforms to limit capacity of hospitals by either closing down facilities or strictly enforcing certificate-of-need (“CON”) requests. ${ }^{157}$

As part of Maine's health care initiative, the government limited CON requests in an attempt to minimize needless expansion of health care capacity. ${ }^{158}$ $\mathrm{CON}$ restriction is a divisive topic as many fear that too much government regulation will thwart legitimate efforts to expand health care services that are needed to be relevant in an ever-changing technological environment. ${ }^{159}$ States like Maine argue that they already have too many facilities that are being underutilized, and that increased building will only add to the over-abundance of under-performing health care facilities. State reform policies must strike a balance between allowing new facilities to keep current with the state-of-art standard of care but not so abundant that every metropolitan area has specialty facilities that do not support the population's needs.

Other states have taken more radical steps. The state of New York took a controversial step in late 2006 by proposing the closing of twenty hospitals as part of a cost containment effort. ${ }^{160}$ Citing that 20,000 of the 63,000 hospitals

(discussing that 2005 witnessed $\$ 100$ billion in new hospital construction, often times occurring in communities that did not need new patient beds). See also Philip Betbeze, Competition: D.I.Y. Docs, HealTHLEADERS MAGAZENE, Apr. 2005, http://www.healthleadersmedia.com/mag azine/view_magazine_feature.cfm?content_id $=66325$ (last visited Apr. 20, 2008) (noting the upsurge in physician-owned specialty hospitals).

156. Catharine W. Burt \& Linda F. McCaig, Staffing, Capacity, and Ambulance Diversion in Emergency Departments: United States, 2003-04, Advance Data FROM Vital AND HEALTH STATISTICS, CTR'S FOR Disease CONTROL \& PREVEnTION, (2006), available at http://www. cdc.gov/nchs/data/ad/ad376.pdf.

157. See generally Sujit Choudhry et al., Specialty Versus Community Hospitals: What Role for the Law?, HEALTH AfF., Web Exclusive, Aug. 9, 2005, at w361, (discussing the need to revisit $\mathrm{CON}$ as a way to control costs associated with unnecessary growth in the specialty hospital industry).

158. The Dirigo Health Act, ME. Rev. Stat. AnN, tit. 24 A, § 6901-6971 (2003). See also Maine.gov., http://www.dirigohealth.maine.gov/dhsp01d.html (last visited Apr. 20, 2008).

159. See John V. Jacobi, Consumer-Directed Health Care and the Chronically Ill, $38 \mathrm{U}$. MiCH. J.L. REFORM 531, 537-38 (2005) (describing the mixed effects of certificate-of-need legislation on controlling costs).

160. Richard Perez-Pena, Plan Could Close 20 or More New York Hospitals, 
beds were not in use and noting the hemorrhaging of red ink by many underperforming hospitals, a commission appointed by then Governor Pataki stated that the fiscal stability of the health care industry required such actions. ${ }^{161}$ Opponents argue the hospital closures will impede care for mostly poor individuals and would have a greater impact on smaller communities where the hospital serves as a major employer. ${ }^{162}$

Radical steps like the ones noted here may be seen in other states as they attempt to stretch Medicaid dollars and weed out inefficient facilities that have failed to stay fiscally responsible and relevant. With a major shift of care from inpatient to outpatient services, the increase in specialty hospitals, the challenges of providing rural health care, and with the new advances in technology, the issue of how to strike a balance between controlled expansion, without impeding entrepreneurial enterprise and access to effective technology-driven treatments, will be challenging. ${ }^{163}$ With increased costs and the competition to secure affluent areas that have health insurance coverage, the public and private sector must find common ground in being able to provide services that promote competition but also create an environment of responsible growth.

\section{Health Provider Shortage: The First Stumbling Block to Meaningful Re- form}

Finding properly trained health care professionals is an ongoing problem for most communities throughout the United States, and threatens the success of any health care reform proposal. Predictions continue to indicate that shortages for nurses, physicians, pharmacists, and other health care technologists will continue for the next several years. ${ }^{164}$ Often the communities with the most serious shortages generally also experience greater rates of poverty and poorer health status. These communities increase overall health care costs as individuals tend not to seek health care until urgency strikes and then access care through hospital Emergency Departments which is the most expensive and least efficient manner to obtain care. As patients postpone care, simple health conditions that are easily treatable in early stages often proliferate into complex illnesses that require more expensive inpatient hospital care. Further, with fewer physicians entering primary care practice, the uninsured and underinsured are hindered from obtaining basic primary care services. As individuals remain without access to affordable basic primary care services, the current health sys-

NYTIMES.COM, Nov. 29, 2006, http://www.nytimes.com/2006/11/29/nyregion/29hosp.html?ex= $1322456400 \&$ en $=7 \mathrm{c} 08722 \mathrm{a} 4489 \mathrm{a} 517 \&$ ei $=5088 \&$ partner=rssnyt\&emc=rss (last visited Apr. 26, 2008).

161. Id.

162. Id.

163. FinANCING THE FUTURE, supra note 20, at 6-12.

164. American Academy of Family Physicians, Higher Demand for Family Physicians Bodes Growth Despite Sluggish Pay Increases, ANNALS OF FAM. MED. 89, 89-90 (2005). See also Howard S. Berliner \& Eli Ginzberg, Why this Hospital Nursing Shortage is Different, 288 JAMA, 2742, 2742-44 (2002). 
tem will continue to function as a reactive model focused on treating the advanced stages of disease rather than utilizing early intervention strategies that lead to better outcomes that mitigate more costly care.

Medically underserved communities that suffer from health professional shortages tend to be concentrated in rural communities and inner city areas where there are increased numbers of economically disadvantaged individuals where the shortage of primary care providers and nurses is much more pronounced. ${ }^{165}$ The supply and distribution of health professionals varies greatly based on the various geographic, demographic, and socioeconomic factors. Health professionals are more likely to be concentrated in affluent areas and less likely to be concentrated in areas where the population is less dense and areas where the population has higher proportions of low income and racial and ethnic minorities. ${ }^{166}$ Further, a landmark 2002, Institute of Medicine Report on racial and ethnic disparities found that even among well-controlled studies "the vast majority of published research indicates that minorities are less likely than whites to receive needed services, including clinically necessary procedures, even after correcting for access-related factors, such as insurance status." 167 With decreased access to care, ethnic populations suffer disproportionately from poorer health status and higher health care costs. ${ }^{168}$

As part of reform efforts, many states have expanded the scope of practice for care provided by non-physician health care professionals by recognizing the value these providers will have in creating a more effective and efficient interdisciplinary health care delivery model. In these discussions, the role of nurse practitioners ("NP") and physician assistants ("PA") have become more widely viewed as a viable, competent provider source for providing cost-effective health care services. Both NPs and PAs have advanced clinical training that allows them the ability to practice in a wide variety of clinic settings but does so from different legal obligations defined under various state laws. For NPs in

165. See DeNAVAS-WALT ET AL., supra note 5, at 19-30.

166. See Michael E. Wade et al., Influence of Hometown on Family Physicians' Choice to Practice in Rural Settings, 39 FAMILY MED. 248-54 (2007).

167. Institute of Medicine, Unequal Treatment: What Health Care System Administrators Need to Know about Racial and Ethnic Disparities in Healthcare, (2002), available at http://www.iom.edu/Object.File/Master/14/973/DisparitiesAdmin8pg.pdf.

168. Many minority groups simply do not have the same access to care as the general white population. For example: African Americans are thirteen percent less likely to undergo coronary angioplasty and one-third less likely to undergo bypass surgery than are whites; among preschool children hospitalized for asthma, only seven percent of black and two percent of Hispanic children, compared with twenty-one percent of white children, are prescribed routine medications to prevent future asthma-related hospitalizations; the length of time between an abnormal screening mammogram and the follow-up diagnostic test to determine whether a woman has breast cancer is more than twice as long in Asian American, black, and Hispanic women as in white women; African-Americans with HIV infection are less likely to be on antiretroviral therapy, less likely to receive prophylaxis for Pneumocystis pneumonia, and less likely to be receiving protease inhibitors than other persons with HIV. See Agency for Healthcare Quality and Research, Addressing Racial and Ethnic Disparities in Health Care, http://www.ahrq.gov/ research/disparit.htm (last visited Apr. 20, 2008). 
particular, many states allow for independent practice as their undergraduate nursing background and Master's degree training fits well within several clinical specialties including primary care-related areas.

Given the shortage of primary health providers in the state, future policy decisions should focus on expanding the scope of services and care that can be provided by non-physician providers who have the education, skill, and competence to provide such services. Clinically, NPs have demonstrated the ability to provide high quality care commiserate with their physician colleagues and are well positioned as a profession based in evidence-based research to work within a variety of settings as part of a valued care team which has already been demonstrated in the medical home model. ${ }^{169}$ In order to expand access to primary care, NPs and PAs must have the ability to serve as primary care providers under Medicaid and other state health reform programs. NPs and PAs can help fill the gap created by the chronic shortage of primary care physicians that is foreseeable into the near future.

\section{Emergency Department Utilization Rates}

Over 4,000 emergency departments ("ED") in the U.S. have become the default primary care clinic for many of the forty-seven million uninsured. The number of uninsured visits to the ED is typically double that of the insured. ${ }^{170}$ One report reveals that at least ten percent of all ED visits can be attributed to the uninsured. ${ }^{171}$ On the inpatient side, the uninsured account for at least five percent to thirteen percent of hospital discharges. Identifying why individuals access EDs is telling as to why there needs to be increased access to primary care for the uninsured. The Centers for Disease Control ("CDC") released an ambulatory surgery utilization report that identified major areas of utilization for outpatient and ED care which includes the following list of visit types by percentage rate: ${ }^{172}$ mental health-related, $7.6 \%$; injury, poisoning, or adverse effects of medical treatment, $12.1 \%$; other acute or benign conditions, $16.6 \%$; infectious conditions, $18.1 \%$; preventive care, including check-ups, prenatal care and post-surgical care $25.2 \%$; and chronic disease treatment, $29.4 \%$. Another key report by the Institute of Medicine studying ED overcrowding found the following: one in five patients were uninsured; ninety-one percent of surveyed EDs reported overcrowding with forty percent stating this occurred daily; non-emergent patients were frequently crowding out emergent care pa-

169. Mary Mundinger et al., Primary Care Outcomes in Patients Treated by Nurse Practitioners or Physicians: A Randomized Trial. 283 JAMA 59, 59-68 (2000) (demonstrating NPs achieved clinical outcomes as good as or better than their physician colleagues).

170. Catharine W. Burt, Linda F. McCaig, \& Elizabeth A. Rechtsteiner, Ambulatory Medical Care Estimates for 2005, AdVANCE DATA FROM VITAL AND HEALTH STATISTICS, CTR's FOR DiSEASE CONTROL \& PREVENTION, (June 2007), http://www.cdc.gov/nchs/data/ad/ad388.pdf.

171. Catherine G. McLaughlin \& Karoline Mortensen, Who Walks Through the Door? The Effect of the Uninsured on the Hospital, 22 HEALTH AFF. 143, 143-55 (2003).

172. See Burt et al., supra note 170, at 2-4. 
tients who required immediate care; and ED patients tend to be older and sicker in need of more expensive work-ups. ${ }^{173}$ Tracking patient encounters across EDs is an important indicator to demonstrate how individuals access emergent and non-emergent care and also serves as an important measurement of how specific ED utilization rates compare with the primary care system. This type of information will be critical to analyzing geographical and socioeconomic factors that drive non-emergent visits to EDs.

While the burden of caring for the uninsured is shared by many providers, hospitals, (for-profit, nonprofit, and safety net hospitals) are often hardest hit by being forced to provide uncompensated care. Under the Emergency Medical Treatment and Active Labor Act ("EMTALA"), any hospital with an emergency room must at minimum screen, and if necessary, stabilize anyone presenting to the ED regardless of ability to pay. ${ }^{174}$ Too often, hospital EDs become crowded with people in need of non-emergent primary care but nevertheless must be cared for under EMTALA. As a result, the amount of uncompensated and charity care provided by hospitals has increased dramatically due to the uninsured. Charity care has become a popular topic for the fact that more uncompensated care is being provided beyond the levels many nonprofit hospitals, who are required to provide some level of free care, can maintain. As hospitals have been forced to provide more charity care, there has been a "spillover effect" to the community as providers ultimately earn less revenue and insured individuals pick up the tab in either increased health insurance premiums or in increased taxes often directed to pay to cover care for the uninsured. ${ }^{175}$ In addition, hospitals are facing increased competition and more narrow margins in a market increasingly filled with competition with large physician groups and physician-owned specialty hospitals. Once lucrative service lines that were historically in a hospital's control and that were used to offset losses incurred in delivering care to the uninsured and in less lucrative areas have been carved out of the hospital revenue stream. ${ }^{176}$

In the wake of increased utilization, some hospitals have adjusted to the increased use of their EDs for non-emergent services by setting up "fast-track" clinics or opening urgent care wings adjacent to their EDs. These clinics often provide care to the insured and uninsured alike as it presents the only convenient alternative for many who need care during after-work hours or for those without a consistent primary care home. While some hospitals with a higher insured base may realize increased payment with higher ED utilization rates, EDs however, are more costly and do not present the most economical model to

173. Inst. of Med., Hospital-Based EMERgency CARE: At the BREAKING PoINt (The National Academies Press) (2006).

174. See 42 §1395dd; see also 42 C.F.R. 489.24.

175. Mark V. Pauly \& Jose A. Pagan, Spillovers and Vulnerability: The Case of Community Uninsurance, 26 HEALTH AFF. 1304, 1304-14 (2007).

176. Charles N. Kahn, Intolerable Risk, Irreparable Harm: The Legacy of PhysicianOwned Specialty Hospitals, 25 HEALTH AFF. 130, 130-33 (2006). 
provide primary care. Health policy efforts should examine ED utilization data to devise new strategies to channel individuals to less costly primary care.

\section{Bringing Back the Integrated Delivery System: Can it Still Work?}

One critical problem facing the current health delivery system is the fact that many providers, insurers, hospitals, and vendors are providing services in an uncoordinated manner in various "silos of care." This development has led to needless duplication and waste, often to the detriment of patients. This fragmentation in care has been brought on by historical changes in the health discussed above with the onset of the managed care and has been exacerbated by payment structures that reward institutions with increased payment for highend technological and specialty care services. ${ }^{177}$ Historically, there has been little effort between providers or health care systems to share patient information or offer strategies to change provider behavior that could control costs and increase efficiency. ${ }^{178}$ Still today, market forces have largely splintered relationships between hospitals and physicians, creating perverse incentives for competition that in many cases have led to an inadvertent "race to the bottom." Today's market continues to uphold delivery structures and payment methodologies that promote higher cost episodic care and expansion of high-end practice lines that optimize hospital and provider margins rather than encourage the most efficient delivery of care.

\section{Past Attempts in Developing an Integrated Delivery System}

The integrated delivery system ("IDS") became a model of health care delivery that emerged from of the managed care movement. ${ }^{179}$ During the period of reform of the 1980's and 1990's, with the managed care expansion and the possibility of health reform brought about under President Bill Clinton, stakeholders began to re-examine their various relationships and service lines. As a result, several expansions and contractions occurred among many of the among physician groups, hospitals, and insurance companies which led to mergers and joint ventures designed to increase coordination of services and enhance economies of scale that made providers better aligned to compete for managed care contracts. ${ }^{180}$ The movement caused many health care entities to more intensively control patient care management by engaging in what has been termed "horizontal integration" and "vertical integration." 181 Horizontal integration largely occurred with mergers and alliances between hospitals which led to the forma-

177. HALVORSON, supra note 145 , at $12-30$.

178. Id. at 210-18.

179. FURROW ET AL., supra note 2, at 535.

180. FURROW ET AL., supra note 2, at 535, 541.

181. Lawton R. Burns \& Mark V. Pauly, Integrated Delivery Networks: A Detour on the Road to Integrated Health Care?, 21 HEALTH AFF. 128, 128-43 (2002). 
tion of local networks and multi-hospital systems. Horizontal integration also occurred among independent and smaller physician groups which led to the creation of large physician groups or partnerships. Vertical integration took place with hospitals purchasing physician practices or creating alliances with physician groups which led to the upsurge in physician-hospital organizations and health maintenance organizations. ${ }^{182}$

The health care system that emerged from this provider shift was one of complicated relationships between physicians, hospitals, and payers arranged under complex legal contracts and arrangements where patient care, treatment goals, and control over economic incentives were not always shared between and within these entities. ${ }^{183}$ What emerged were insurers, physicians, and hospitals all competing to establish their prominence in the marketplace. For instance, some hospitals systems became completely vertically integrated by having multiple hospitals in a specific geographic area but also owned multiple specialty and primary physician practices, outpatient clinics offices, and ambulatory surgery centers. These systems also by virtue of their geographic size also offered their own provider health plans to employers. Further, in order to remain relevant, physicians often partnered with these larger systems in more loosely affiliated contractual partnerships where the larger entity shared more accountability and risk. For example, a hospital or insurer would often purchase a physician's existing infrastructure including files, equipment, and pay for office staff, but the physician would then work for the system as an independent contractor. Because hospitals and insurers at the time of this shift typically had deeper pockets to reorganize a new business model in the marketplace, there was a rush to try and capture large market shares in order to be more attractive to employers purchasing managed care insurance plans. As a result physicians were often left in the middle to try and bargain for the best deal between insurers and hospitals. Many agree that the integrated delivery system that emerged from this re-alignment ultimately failed to enhance patient care or control costs. Many reasons are cited, a few of which include: hospitals moved to fast to restructure the system; hospitals spent too much money to acquire physician practices; hospital-based HMOs did not have the expertise to accurately pool risk and meet service demands; a recurring inability to coordinate physician and hospital goals; and consumer backlash against restrictions on care. ${ }^{184}$

While past attempts at implementing integrated delivery models were met with mixed results as a result of the managed care changes, there is growing and renewed support that providing quality, cost-effective care in the future will only be achieved with some level of coordination and integration among all stakeholders that comprise the health care system. ${ }^{185}$ Although many would

182. FURROW ET AL., supra note 2, at 535.

183. HALL ET AL., supra note 15, at 1066-69.

184. Burns \& Pauly, supra note 181, at 132-36.

185. Id. 
argue the United States has the biggest and best health care system in the world, these facts have often not correlated the best care as the United States consistently scores poorly in major health indicators. ${ }^{186}$ The future of health care must be driven by efficient models of patient care that encourage coordination and integration. One such example can be found already operating within the federal government- the Veteran's Administration ("VA") hospital system.

Among the best health system models typically recognized, the VA system represents a change in thinking and practice that has been acknowledged by many researchers as a health care system that is moving in the right direction. ${ }^{187}$ VA currently cares for over 5.3 million veterans at 1400 sites in every state which is divided into twenty-two care networks serving as the largest public integrated delivery system in the U.S. ${ }^{188}$ Although VA has room to improve with the execution of services across all of its hospital and clinic sites, recent movements to make the system more efficient have garnered the attention of other health systems. VA's re-structuring success has largely been driven by the implementation of IT and the expansion of uniform medical records. For example, VA now implements a system whereby a VA patient from California can walk into the VA Hospital in Indiana and have their records immediately at the fingertips of a health care provider. VA has also utilized this technology at the bedside to increase collaboration, decrease mistakes, and enhance communication between providers. VA was one of the first systems to store all medical-related data which now contains over 779 million clinical documents, 1.5 billion orders, and over 425 million images.

VA has used this innovation in technology to perform better than other private entities. ${ }^{189}$ Further, the VA's cost per patient has not increased over the past ten years remaining steady at about $\$ 5000$, while medical care for families in the private sector has jumped about forty percent. ${ }^{190}$ In addition, the VA, by virtue of being a government funded agency, has special relationships and ability to integrate innovative practices on a large scale. One area where this has proven beneficial is in the purchasing of medications. Congress has given the Secretary of the VA the ability to negotiate directly with drug companies for pricing on medications which has allowed veterans to purchase medications at a much lower cost than private insurers or Medicare recipients. The VA system

186. Cathy Schoen et al., U.S. Health System Performance: A National Scorecard, 25 HEALTH AFF. W457, w457-75 (2006); see also Elizabeth A. McGlynn et al., The Quality of Health Care Delivered to Adults in the United States, 348 NEw ENG. J. OF MED. 2635, 2635-45 (2003).

187. Steven Asch et al., Comparison of Quality of Care for Patients in the Veteran's Health Administration and Patients in a National Sample, 141 ANNALS OF INTERNAL MED. 938, 942-45 (2004) (comparing care of VA patients to others and noting that the VA system does a much better job of coordinating care across a complex national institution).

188. Joel Kupersmith et al., Advancing Evidence-Based Care for Diabetes: Lessons From the Veterans Health Administration, 26 HEALTH AFF. w156, w156-68 (2007).

189. See Douglas Waller, Vetting the VA, AARP BULlETIN, May 2007, http://www.aarp. org/bulletin/bulletin/yourhealth/vetting_va.html (last visited Apr. 26, 2008).

190. Id. 
has become a model of quality and efficiency by consistently examining and comparing the best practices and guidelines in clinical practice across all of their hospitals in the country, providing caregivers the information they need to provide high-level care. The VA system serves as an excellent model for both state and federal governments as to how national policies can be successfully formulated across large and complex health care delivery systems.

\section{Primary Care as the Center Piece for Integration}

With reform efforts underway around the country, many are focused on increasing access through a multi-pronged approach ranging from insurance subsidies, to increased use of information technology, to increased coordination among providers, and appropriate use of health services. Many of these efforts could be organized as part of an integrated delivery model where individuals are given access to basic primary health care. A key part missing from the current delivery system equation is the lack of access to consistent, basic primary care services. If state legislatures want to get the most from their tax payer dollars, they would be well served to re-design health reform efforts around a new delivery model focused on primary care.

There is a broad consensus that access to timely, primary and preventive health care services results in lower health care costs and better health outcomes than uncoordinated, delayed care. ${ }^{191}$ A study of vulnerable populations documented the link between shortages of primary care providers and preventable hospitalizations. For example, Medicare beneficiaries in fair or poor health are more likely to experience a potentially preventable hospitalization if they live in a county designated as a primary care shortage area. ${ }^{192}$ In fact, even when taking into account the number of specialists versus primary care providers in a particular area, increasing the supply of specialists does not improve the United States' position in relation to relative health as compared to other industrialized countries as increased specialist supply has been shown to promote greater disparities in health status and outcomes. ${ }^{193}$

\section{a. The patient-centered primary care "home" concept}

Much of the reform efforts now being discussed at the state level have instituted a renewed focus on coordination of all care through primary care model of care. Engaging individuals in a consistent, trusting manner where a team of providers are competent and prepared to provide holistic, culturally sensitive,

191. See Michael L. Parchman \& Steven D. Culler S., Preventable hospitalizations in primary care shortage areas: An analysis of vulnerable Medicare beneficiaries, 8 ARCHIVES OF FAMILY MED. 487, 487-91 (1999).

192. Id.

193. Barbara Starfield et al., The Effects of Specialist supply on Populations' Health: Assessing the Evidence, HEALTH AFF. w95, w95-107 (2005). 
and community-specific care must be the cornerstone of any new paradigm of care. While no one primary care model perfectly embodies this approach, there are current models and common themes that are beginning to take shape at the national level. One of the more interesting concepts to resurface is the "patientcentered medical home." The concept of providing patients with a consistent primary care provider is not a new concept given the recent era of "gatekeepers" that evolved with managed care. There are additional historic roots for creating primary care "homes" for patients as the "medical home" concept has used for nearly four decades and can be traced back to efforts by the American Academy of Pediatrics which began modeling a clinic program designed to care for children with special needs. ${ }^{194}$ Recently, there has been a new push to establish what is being called the "medical home"195 and "coordinated primary care." "This contemporary model no longer focuses exclusively on the pediatric population as noted above, but is now being re-visited as a new model for the general primary care for the entire U.S. population. As it now stands, there is no one specific model that is the recognized "gold standard," but rather the current care home discussions are based in over-arching principles. There are, however, several pilot studies and new programs under way as part of the movement towards a medical home model. ${ }^{197}$ Slowly, there are common a ttributes emerging that appear to be moving in sync with the health reform discussions about the need for increased access to primary care. Many of the major health profession organizations including, the American Academy of Family Physicians, American Academy of Pediatrics, the American College of Physicians, and the American Academy of Nurse Practitioners have revisited how the medical home model should be conceptualized in this new era of health care restructuring. From these proposals general concepts from the primary care home model include: 1) providing care beyond chronic disease management with a focus towards preventive care targeting health promotion and maintenance; 2 ) providing care through a collaborative team model including nurse practitioners, pharmacists, public health nurses, social workers, and physicians; 3 ) the primary care home will be the coordinating mechanism for all care with specialty providers, therapists, and hospital services; 4) care should be

194. See American Academy of Pediatrics, http://www.medicalhomeinfo.org/ (last visited Apr. 20, 2008).

195. See Karen Davis \& Steve Schoenbaum, Medical Homes Could Improve Care for All, The Commonwealth Fund, July 20, 2007, http://www.commonwealthfund.org/aboutus/ aboutus_show.htm?doc_id=510655; see also Medical Home Gains Prominence With AAFP Oversight, ANNALS OF FAM. MED., 6:90-91 (2008), http://www.annfammed.org/cgi/ content/full/6/1/90 (last visited Apr. 20, 2008).

196. Am. ACAD. of Nurse Practitioners, NuRse Practitioners: Promoting ACCESS to COORDINATED PRIMARY CARE, (Dec. 5, 2007) (on file with author).

197. See Bridges to Excellence Launches Medical Home Program, Jan. 31, 2008, $\mathrm{http}: / / \mathrm{www}$. bridgestoexcellence.org/Content/ContentDisplay.aspx?ContentID=119 (last visited Apr. 20, 2008); see also The Commonwealth Fund, Evaluating a Medical Home in Two Health Plans, Dec. 2007, http://www.commonwealthfund.org/grants/grants_show.htm?doc_id=584761. (last visited Apr. 26, 2008). 
maximized through a continuous care relationship, not simply episodic care; 5) care may be provided in a variety of settings where the use of advanced technology, EMR, and tele-health should be standard; 6) linking patients to community sources to address mental health, addiction, and other basic needs such as food, shelter, and medications; and 7) enhancing access through extended hours and open access scheduling.

While the medical home is appealing for many reasons, the application may be challenging in many cases as there are not enough primary care physicians to support medical homes needed to meet the demand in care. Further, as noted earlier, the distribution of providers reveals many physicians are clustered around major cities with a disproportionate distribution number not choosing to practice in poorer urban and rural settings which may hinder proper coverage. Also creating problems are the continuing issues associated with reimbursement and coordination of care between specialties and other health care professionals such as social workers, health educators, and therapists. On the reimbursement side, many physicians and other providers feel the current health care system is improperly incentivized. For example, there is little to no reimbursement for activities geared towards health prevention and promotion. Many argue that the current reimbursement model incents performing procedures and racking up large volumes for episodic care for common infections and lab draws. Providers argue that until the reimbursement system is properly aligned towards health promotion and prevention, it will be difficult to properly engage their patients and continue to remain financially sound on the clinical side of their practice.

\section{model \\ b. Community Care of North Carolina: A successful primary care}

While many states have addressed access to primary care, North Carolina has been developing a model that holds promise for application with the uninsured and serves as a model for expanding a state-wide system of care. North Carolina's Community Care of North Carolina ("CCNC") began as "Access" in 1991 which evolved from a demonstration program in $1998 .{ }^{198}$ The CCNC program evolved from the previous case management program that was part of a state-wide effort to better manage the care provided to Medicaid enrollees. Over the past several years, the CCNC program has garnered national attention as a provider-led alternative that has been able to increase the quality of care while also controlling costs. The CCNC program is organized around the following principles: 1) ownership is vested with community participants; 2) roles and responsibilities of the participants (both government and providers) are clearly defined; 3 ) accountability is clear and measured; 4) in-depth technologi-

198. See Community Care of North Carolina, http://www.communitycarenc.com/ (last visited Apr. 26, 2008). 
cal assistance is provided by the state on a continuous basis; and 5) meeting community needs is the focus of all activities. ${ }^{199}$

During its time in existence, the CCNC program has placed an emphasis on quality outcomes, best practices, and has made providers accountable for the patients they care for. For example, the CNCC program has required care initiatives that measure and provide treatment programs for asthma, COPD, congestive heart failure, diabetes, in addition to tracking of emergency department and medication utilization and special tracking of high-cost patients. The program has the evidence to support that this unique community-based network is achieving results. One study done by the Mercer Human Resource Consulting Group found that the program in fiscal year 2006 saved \$154-170 million. ${ }^{200}$

Currently the CCNC program has fourteen networks with over 3,000 physicians that serve 785,000 patients. ${ }^{201}$ All local networks operate as 501(c)(3) non-profit organizations that at minimum, include area primary care providers, a hospital, the county Department of social services (Medicaid) office, and the county health department. ${ }^{202}$ Each network is required to assess, with the help of the state, the specific needs of the population they serve and then develop subsequent treatment standards to best meet the needs of the population with special attention placed on high-cost individuals. Each network elects a physician to serve as the clinical director who serves on statewide board of directors responsible for overseeing the direction of the system's programs. Moreover, other key professionals play a key role in the care model which includes case managers, quality improvement champions, and network coordinators. Although financing is run through the Medicaid program, CCNC, in addition to the payment of fee-for-service, pays physicians a coordination fee of $\$ 3.00$ per patient, per month. Physicians in the state, however, remain frustrated that the payment fee schedule is not incentivized to promote more primary care-related activities. $^{203}$

199. Stephen Wilhide \& Tim Henderson, Community Care of North Carolina: A ProviderLed Strategy for Delivering Cost-Effective Primary Care to Medicaid Beneficiaries, available at $\mathrm{http}: / / \mathrm{www}$.nahit.org/cms/index.php?option=com_docman\&task=doc_view\&gid=107\&Itemid= 197 (last visited Apr. 26, 2008).

200. MERCER REPORT, CCNC/ACCESS COSt SAVINGS FOR FisCAL YeARs 2005, 2006, available at $\mathrm{http}: / /$ www.communitycarenc.com/PDFDocs/Mercer\%20SFY05_06.pdf.

201. Community Care At a Glance, Jan. 2008, http://www.communitycarenc.com/ PDFDocs/CCNC\%20AT\%20A\%20GLANCE.pdf.

202. Wilhide \& Henderson, supra note 199, at 5-7.

203. James Arvantes, Medical Homes, Physician-led Networks Can Improve Care, Cut Costs, AAFP.ORG, Mar. 6, 2007, http://www.aafp.org/online/en/home/publications/news/ news-now/government-medicine/20070306northcarolina.html (last visited Apr. 20, 2008). 


\section{Federal Action that Could Impact State Initiatives}

\section{The Continued ERISA Problem}

At the heart of reform process lies the complexity of the federal-state relationship that is replete with a web of laws and invites many potential reform roadblocks. As demonstrated previously with the Maryland "Wal-Mart case," conflict with the federal ERISA law may preempt the ability of future state health reform legislation to regulate private health insurers. ${ }^{204}$ Historically, the ERISA language has been broadly interpreted by the Supreme Court to allow employers who are self-insured to be bound only by the federal ERISA law which preempts most state regulation. While ERISA does not preempt states from passing laws that mandate certain benefits be offered in the state or to raise costs, the ERISA statute has limited most states' abilities to regulate private employer's conduct when administering their self-insured plan. ${ }^{205}$ Many would argue the vague and contested "related to" language of ERISA has created an environment where many employers who qualify as self-insured entities under the ERISA statute, enjoy a subset of protections for employers, providers, and insurers that has been used to circumvent state regulation under the guise of ERISA preemption. $^{206}$

Other cases in addition to the Wal-mart case, have surfaced in the past few months which reveal the courts are continuing to side with upholding ERISA preemption where pay-or-play mandates are issued. In two federal court cases, the courts have held that ERISA pre-empts state laws that created a pay-or-play schemes similar to the one noted in Fielder. In Retail Industry Leaders $v$. Suffolk County the federal District Court for the Eastern District of New York held that that the city ordinance that required certain large retail stores with specific revenue or inventory space to ensure certain employee health care costs were in line with the county's uninsured workers system, was ERISA preempted. ${ }^{207}$ The court finding the Suffolk Country plan similar to Maryland's, followed the Fourth Circuit's logic in Fielder and determined that the mandatory payment required whether it be through the ERISA plan, a health savings account, or other contribution option, created a conflict for employer's not allowed under ERISA. Similarly, in Golden Gate Restaurant Association v. City and County San Francisco, the court held that a San Francisco city ordinance that would have required all city firms to spend a specified

204. Kinney, supra note 99 , at $917-18$.

205. See New York Conference of Blue Cross \& Blue Shield Plans v. Traveler's Ins. Co., 514 U.S. 645 (1995); Metro. Life Ins. Co. v. Massachusetts, 471 US. 724, 739-40 (1985). See also Pilot Life Ins. v. Dedeaux, 481 U.S. 41, 48 (1987).

206. Kinney, supra note 99, at 924-27.

207. Retail Indus. Leaders v. Suffolk County, No. 06-CV-00531 (E.D. N.Y. July 14, 2007). 
amount per hour, per employee to cover some health services or be required top pay the city an amount that would fund a public health insurance subsidy for the uninsured, was ERISA preempted. ${ }^{208}$

The ERISA conundrum illustrates an area where the federal government could work with states by revisiting the specific aspect of the ERISA statute that prevents states from implementing innovative changes. At this point in the evolution of health reform, states are in the best position to re-tool the health care infrastructure and will need the benefit of federal support with regulatory issues such as ERISA. With Congress unwilling to devise more well-defined boundaries surrounding the ERISA preemption issues as it pertains to state regulation of employers and insurers, ${ }^{209}$ others have advised on ways to structure the reform efforts that may face ERISA challenges. For example, Patricia Butler has listed a series of considerations the courts may find favorable to uphold a state initiative without finding ERISA preemption. ${ }^{210}$ For example, Butler recommends states consider taking the following steps when designing an employer pay-or-play mandate: 1) make sure the plan does not explicitly refer to ERISA; 2) sponsors of the legislation should stay neutral as to whether employers are forced to pay the assessment or provide coverage; 3 ) any tax credit provided for covering employees can be applied to any health spending not just spending on traditional health plans; 4) the credit is not premised on the employer meeting the structural requirement of the law such as premium sharing; 5 ) if the employer pays the assessment (in lieu of providing employee coverage), this will not prevent the employee from participating in the state program; and 6) it may be better to call any assessment a tax versus a fee in order to bring the payment under the state's authority. ${ }^{211}$ Although there is no guarantee that the courts will deviate from the ERISA stance discussed in the case above, with more health reform statutes coming on line, the court system may start upholding statutes as a signal to Congress to take action or to allow states increased flexibility to handle the health care issue. The courts may also uphold state actions to avoid conflicting federalism issues that were not fully considered with respect to health care coverage when ERISA was created. ${ }^{212}$

208. Golden Gate Restaurant Ass'n v. City and County of San Francisco, No. CV-0606997-JSW (N.D. Cal. December 26, 2007) (the City was successfully able to persuade the Ninth Circuit Court of Appeals to issue a stay of the District Court decision pending the outcome of the appeal).

209. Jana K. Strain \& Eleanor D. Kinney, The Road Paved With Good Intentions: Problems and Potential for Employer-Sponsored Health Insurance Under ERISA, 31 LOY. U. CHI. L.J. 29, 55, 67 (explaining how ERISA could be reformed to promote state regulation while still honoring the spirit of ERISA to protect employee benefit plans).

210. Patricia A. Butler, ERISA Implications for State Health Care Access Initiatives: Impact of the Maryland Fair Share Act" Court Decision, National Academy for State Health Policy, Nov. (2006).

211. Id. at 11 .

212. Id. 


\section{Issues of Federalism}

Another wrinkle to add to the already complex federal-state relationship is the issue of the boundaries of federalism. A series of Supreme Court cases have recently limited the power of Congress via the Commerce Clause to pass legislation that mandates state regulation. ${ }^{213}$ Under these Supreme Court rulings, Congress may be hampered in passing legislation that would promote continued state innovation in the health care arena.

Generally, it has been recognized that states retain the police power to control and provide for the health of its citizens. ${ }^{214}$ With renewed reform efforts in play, concerns have arisen over whether a uniform federal health care system or other federal health care plan will erode state autonomy to exercise its well recognized police power. While these concerns are legitimate, federal action should not be restricted in such a manner that the federal government becomes limited in its ability to participate in the process by enacting legislative solutions to this complex crisis that affects the entire nation. The health care crisis runs deeper than each individual state's particular local, cultural, religious, or geographic needs. Clearly, there are issues of state control as demonstrated with assisted suicide and medical marijuana reform that may be better left to the states, however, the issue of affordability and access to basic health services goes to the heart of the United States economy and general welfare. Further, the federal government has been able to successfully pass legislation to solve complex social problems that in the past that has traditionally been left to the states. Some examples include federal legislation to handle the education crisis in the No Child Left Behind Act, racial inequality in the Civil Rights Act, and the Racketeer Influenced and Corrupt Organizations Act as an example of containing the effects of national organized crime. ${ }^{215}$ These legislative acts were passed to create accountability for underperforming state programs or policies that presented unique issues important to the nation as a whole.

Whatever concerns there may be regarding a federal monopoly of the health care system, ultimately the power of the people to vote and Congress' "power of the purse" 216 provide the political ammunition and spending power

213. See Seminole Tribe v. Florida, 517 U.S. 44, $56-57$ (1996); U.S. v. Lopez, 514 U.S. 549, 566-67 (1995); U.S. v Morrison, 529 U.S. 598 (2000) (each case redefining the ability of Congress to require state action under the power of the Commerce clause).

214. U.S. ConST. amend. X, (" $[t]$ he powers not delegated to the United States by the Constitution, nor prohibited by it to the States, are reserved to the States respectively, or to the people").

215. See No Child Left Behind Act of 2001, Pub. L. No. 107-110, 115 Stat. 1425 (2002) (codified primarily in scattered sections of 20 U.S.C.); Civil Rights Act of 1964, Pub. L. No. 88352, 78 Stat. 241 (1964); Racketeer Influenced and Corrupt Organizations Act ("RICO") (Pub. L. 91-452, 84 Stat. 941 (1970).

216. Marmor \& Oberlander, supra note 1, at 217-219 (Ultimately meaningful health care reform will require the federal government to coalesce a unified plan that coordinates a certain level of service and funding). But cf. Tammy Murray, State Innovation in Health Care: Congress' Broad Spending Power Under A National Health Care System Will Stifle State Laborato- 
needed to pass reform without unconstitutionally trumping state rights. The health care crisis is too big for states to handle alone; when the country falls deeper into a crisis that expands beyond a state or region, federal action is often required. While the judicial branch will likely serve as a check on reform issues, previous decisions thus far, as demonstrated in cases such as Seminole Tribe v. Florida and U.S. v. Lopez, were decided on narrow grounds geared largely as part of a push-back from the courts against an over-reaching legislative branch. Although the legislature must respect the republic's boundaries when enacting legislation, the court likewise cannot legislate or abuse its authority to haphazardly limit legislative reform. The issue of health care presents unique problems that will require a cooperative federal-state relationship where all reasonable federal efforts can be given the necessary opportunity to empower states to deal head-on with the health care crisis. Already the Medicaid and Medicare programs are examples of federal to state partnerships that represent health care dollars being used synergistically to promote health care access and affordability. There is no reason to believe that this same type of state innovation and experimentation will not occur in conjunction with the federal government to the detriment of state autonomy.

While turf wars between the state and federal government are likely to continue in the face of health care reform, this is nothing new and represents the check built into the system that has always served to outline the legislative boundaries. Simply leaving the states alone to determine their own local "answer" creates the same problems where state reform could create economic disharmony leaving one state economically disadvantaged against another. As demonstrated in many of the previous congressional acts, the federal government has an interest in national uniformity. Without question a balance must be struck where the boundaries of federalism are respected but where innovation is not so stymied that meaningful reforms engineered at the national level are never given a chance. The current health care system is an amalgamation of happenstance policy mired in both federal and state legislation driven largely by Medicare and Medicaid laws passed at the federal level. ${ }^{217}$ While the Supreme Court may be moving towards reaffirming the protection of state autonomy, the power of the people in the political process to demand health care reform should be the guiding principle and foundation for change. The complex process of reforming health care should not be legislated from the Supreme Court bench.

\section{Prescription Drug Price Negotiations}

Negotiation of prescription medication prices is another area where federal action can have a meaningful impact on making the health care system more

ries of Democracy, IND. HEALTH L. REV. 263, 283-86 (2006) (arguing that state should control most areas of health reform).

217. Eleanor D. Kinney \& William M. Sage, Resolving Medical Malpractice Claims in the Medicare Program: Can it Be Done?, 12 ConN. Ins. L.J. 77, 81-2 (2005). 
cost-effective and efficient for states. As the Medicare Modernization Act currently stands, Part D drug prices are not set in a prospective payment system by CMS. ${ }^{218}$ When given the choice to use a centralized approach that would allow the Secretary of Health and Human Service to directly negotiate with the pharmaceutical companies, Congress elected to instead allow a third party, pharmacy benefit managers ("PBM"), to handle price negotiations. ${ }^{219}$ While some argue PBMs have incentives to keep drug prices low, the fact that the secretary of CMS cannot negotiate directly (as the Secretary of VA currently can do) certainly invites questions as to the undue influence the pharmaceutical insurance industry has on keeping prices inflated. ${ }^{220}$ While pharmacy costs account for eleven percent of all personal health care spending and with the pharmaceutical industry profits and advertising budgets soaring, the American people deserve a fair shake in being able to have access to affordable drugs. ${ }^{221}$ The Democratic controlled Congress has tried challenging the MMA by passing legislation that would allow the federal government to negotiate better drug prices but has thus far failed. ${ }^{222}$

\section{CONCLUSION-ARE WE THERE YET?}

Like kids in the back seat of a car waiting to arrive at the long awaited destination the question of, "Are we there yet?" appears more appropriate than ever with respect to health care reform. The current state actions to attempt to increase coverage may be the tipping point for jumpstarting significant reform action at the federal level. Regardless of where reform settles in, with the baby boomer population retiring, the number of uninsured continuing to grow, and with uncontrollable health costs, health care reform will remain a top national issue for some time to come. Furthermore, as the global economy continues its rapid expansion, the United States must remain relevant and competitive by keeping pace with its industrialized peers by sustaining a healthy work force and maintaining control on health care costs. The United States needs to send

218. Susan Addler Channick, The Medicare Prescription Drug, Improvement, and Modernization Act of 2003: Will It Be Good Medicine For U.S. Health Policy?, 14 ELDER L.J. 237, 254-55 (2006).

219. Id.

220. Id.

221. THE Henry J. KAISER FAM. Found., IMPACT OF DiRECT-TO-CONSUMER ADVERTISING ON PRESCRIPTION DRUG SPENDING, June 2003, available at http://www.kff.org/rxdrugs/upload/ Impact-of-Direct-to-Consumer-Advertising-on-Prescription-Drug-Spending-Summary-ofFindings.pdf (reporting that spending by the pharmaceutical industry increased from $\$ 9.2$ billion in 1996 to $\$ 19.1$ billion in 2001).

222. Robert Pear, Bill to Let Medicare Negotiate Drug Prices is Blocked, NYTIMES.COM, Apr. 18, 2007, http://www.nytimes.com/2007/04/18/washington/18cnd-medicare.html?hp (last visited Apr. 26, 2008); see also Medicare Prescription Drug Savings and Choice Act of 2007, S. 2219, 110th Cong. (1st Sess. 2007) (legislation re-introduced October 23, 2007, by Illinois Senator Dick Durbin to allow Medicare to negotiate drug prices among other provisions being proposed). 
foreign investors reassuring signals that doing business in the United States will not lead to profit losses due to out-of-control health care costs.

Also key to driving the entire process forward will be the "health" and strength of the relationship that exists between the state and federal government regardless of whether or not state plans continue to proliferate. ${ }^{223}$ If the federal government decides to move towards a more centralized health care system, there will be many challenges given the various geographical constraints and population differences that exist from state to state. Hopefully, however, after the current wave of state experimentation is evaluated, there will be many components (as noted above) that will be worthy of adopting at the national level. Already, the VA system and Medicare and Medicaid programs represent successful benchmarks that prove a national strategy to manage health care is possible.

Further, as Barack Obama and Hillary Clinton move towards the Presidential nomination, it is clear that health reform under their leadership will be an important part of their administration's objectives if elected. Fortunately, Senators Obama and Clinton have helped to renew the health care debate and keep this important topic in the spotlight of important national issues as they campaign in this time of economic distress and war.

\section{A. Reforming the Collective American Health Care Psyche}

All stakeholders involved in the reform process will have to dig deep into the American subconscious and psyche to find deeper answers needed to resurrect a new health care system. In examining this complex environment where health care interactions take place, hidden is a very unique endeavor with values driven by a personal, cultural, and historical context that will require a novel approach and deep understanding to define and redefine what it means to be "healthy." Further, because health care is not an exacting business, like making cars or other products, we must appreciate the problems that we now face in providing care will never be made perfect in a free market system. There will always be a group that cannot participate in a market health care economy and there will always be market externalities that will require unique paradigms of care that fall out of even non-traditional business models. Current business stakeholders, such as third-party payers, while not in jeopardy, will need to radically redesign and perhaps even realize their model is no longer relevant, efficient, or the right answer to serve the country's future health care needs.

The entire country will need to accept that a collective attitude adjustment is mandatory for all citizens and providers. For many health care providers, frustration continues to grow over the recurring chronic health problems that arise from lack of preventive care, obesity, sedentary lifestyles, and the abuse of tobacco products, drugs, and alcohol. While no one would advocate an ab-

223. Kinney, supra note 99 , at 911. 
olishment of the right to privacy, or would warrant severe restrictions on personal choice, the reach of public health and the burden to bear the costs of certain lifestyle choices must be addressed head-on. In doing so, a new era of ethical challenges will be ushered in. Citizens will no longer be immune from the costs associated with their unhealthy or risky health behaviors. Unhealthy behaviors will need to be confronted and citizens must be made to understand that their unhealthy actions are directly connected to not only their personal welfare, but the overall health of their neighborhood, city, state, and nation. A radical new accountability and lifestyle management mentality must take hold in order to change the way the health care system is utilized and engaged by individuals.

Likewise, health care providers must recognize that at the point of care, they no longer have exclusive autonomy for their patient's care nor do they reserve a carte blanche menu from which to purchase any unchecked health care service they desire for their patients. Health providers at every level, however, must be integrated into the decision-making process and must be empowered to create an environment of health care that is cost effective, efficient and medically sound. While programs such as "pay for performance" hold some promise for containing costs, a more evidence-based approach to health care that coordinates health services aligned with national goals and standards of care must be integrated into the provider's office, but mindful that medicine is as much an art as a science, and cannot be administered in a one-size-fits-all manner. Without question, the quality, integration, and collaboration that must take place can only be done through the enhanced use of IT. While the needed transformation may be a decade away, common databases and creative use of computer products and other products such as cell phones need to be woven as quickly as possible into the care delivery process.

The hot-button issue of transparency will also continue to be a major part of the discussions in analyzing the ways in which consumers will be asked to participate in and navigate the health care system. Many advocates are pushing for mandatory reporting by hospitals and other health care service providers in order to level with health care consumers about their actual costs, rates of procedure success, and morbidity and mortality outcomes. With this new era of reporting around the corner, this certainly begs the question of whether health care consumers are really and truly equipped to interpret what can be very complicated language and statistics and whether or not they can actually use the information to make an "informed decision" about their care. Further, the selfreporting of health care organizations will also be subject to scrutiny. If the information health care organizations provide proves to be self-selected snippets leading to untrustworthy data, the public movement towards an environment where pricing is more "clear" will only create further confusion and acrimony. Demanding transparency from private and public institutions is a critical piece of reform that must be implemented in order to create a health care market more understandable to the average citizen that will promote trust in the process as well as increased efficiency of the system. 


\section{B. We Can No Longer Wait}

Although the United States Supreme Court has not recognized health care as a right defined in the United States Constitution, ${ }^{224}$ support for constitutional amendments at the state level mandating health care for all citizens is growing and poised to become reality. Creating a system where universal coverage is standard for all citizens in one of the wealthiest countries in the world should be very achievable given the United States has the most advanced health care system in the world. It is likely the incremental steps currently taking place in the states, will play out over the next few years creating a clearer picture of what the best model of care may hold for a nationalized plan. With the 2008 election process already well under way, there is a strong possibility that a change in the presidency will establish a bully pulpit from which the next President will lead the charge for meaningful reform. While the next President will want to avoid the mistakes of previous administrations, if they can construct a plan that can be easily articulated to constituents and can then develop a critical mass of support in Congress, success may follow. In the meantime, states need to continue to move forward with plans that increase access to care and services for the fortyseven million uninsured. Regardless of the rate or type of change, all reasonable plans should be embraced as the status quo will only continue to hinder the United States. The United States can no longer continue to pay Bentley prices for care only to receive Pinto-like quality in return. Some may argue that health care reform is too expensive, but if we remain in the same rut, we will continue to pay for double-digit increases in health care that merely cost-shifts from one group to another while the quality of care will continue to languish. So the answer to the question of "Are we there yet?" is a resounding "YES!" The time has come to get to work to ensure health care is affordable and accessible to all American citizens, otherwise the health care system will remain lost in a sea of unaccountability and expensive mediocrity. At this time, state reform is the best hope for creating alternative solutions and the political will necessary to push health reform forward to the federal stage. The federal government should listen, learn from, and support these processes so that an eventual national plan can come about sooner rather than later.

224. Harris v. McRae, 448 U.S. 297, 311, 318 (1980) (concluding that Title XIX does not require states participating in Medicaid to pay for medical services for which federal reimbursement is unavailable); Maher v. Roe, 432 U.S. 464, 469 (1977) ("The Constitution imposes no obligation on the States to pay the pregnancy-related medical expenses of indigent women, or indeed to pay any of the medical expenses of indigents."). 